\title{
Visualizing Our Options for Coastal Places: Exploring Realistic Immersive Geovisualizations as Tools for Inclusive Approaches to Coastal Planning and Management
}

\author{
Robert Newell*, Rosaline Canessa and Tara Sharma \\ Department of Geography, University of Victoria, Victoria, BC, Canada
}

Effective coastal planning is inclusive and incorporates the variety of user needs, values and interests associated with coastal environments. Realistic, immersive geographic visualizations, i.e., geovisualizations, can serve as potentially powerful tools for facilitating such planning because they can provide diverse groups with vivid understandings of how they would feel about certain management outcomes or impacts if transpired in

OPEN ACCESS

Edited by:

Annette Breckwoldt, Alfred-Wegener-Institut für Polar- und Meeresforschung, Germany

Reviewed by:

Lindsay Joyce McCunn Vancouver Island University, Canada

Edward Jeremy Hind-Ozan,

Cardiff University, United Kingdom

*Correspondence:

Robert Newell rgnewell@uvic.ca

Specialty section:

This article was submitted to Marine Conservation and

Sustainability,

a section of the journal

Frontiers in Marine Science

Received: 14 July 2017

Accepted: 25 August 2017

Published: 08 September 2017

Citation:

Newell R, Canessa $R$ and Sharma $T$ (2017) Visualizing Our Options for

Coastal Places: Exploring Realistic Immersive Geovisualizations as Tools for Inclusive Approaches to Coastal

Planning and Management.

Front. Mar. Sci. 4:290.

doi: 10.3389/fmars.2017.00290 real places. However, the majority of studies in this area have focused on terrestrial environments, and research on applications of such tools in the coastal and marine contexts is in its infancy. The current study aims to advance such research by examining the potential a land-to-sea geovisualization has to serve as a tool for inclusive coastal planning efforts. The research uses Sidney Spit Park (BC, Canada) as a study site, and a realistic, dynamic geovisualization of the park was developed (using Unity3D) that allows users to interact with and navigate it through the first-person perspective. Management scenarios were developed based on discussions with Parks Canada, and these scenarios included fencing around vegetation areas, positioning of mooring buoys, and management of dog activity within the park. Scenarios were built into the geovisualization in a manner that allows users to toggle different options. Focus groups were then assembled, involving residents of the Capital Regional District (BC, Canada), and participants explored and provided feedback on the scenarios. Findings from the study demonstrate the geovisualization's usefulness for assessing certain qualities of scenarios, such as aesthetics and functionality of fencing options and potential viewshed impacts associated with different mooring boat locations. In addition, the study found that incorporating navigability into the geovisualization proved to be valuable for understanding scenarios that hold implications for the marine environment due to user ability to cross the land-sea interface and experience underwater places. Furthermore, this research demonstrated that building scenarios within a realistic geovisualization required modeling place-based characteristics (including soundscape) as well as spatial properties. This approach can allow users the ability to more comprehensively assess scenarios and consider potential options.

Keywords: geovisualization, coastal management, stakeholder collaboration, interactive tools, virtual environments, sense of place, scenario assessment, landscape visualization 


\section{INTRODUCTION}

Effective coastal planning is inclusive and incorporates the variety of user needs, values, and interests associated with coastal environments (Cicin-Sain and Knecht, 1998; Bowen and Riley, 2003). Accordingly, tools that can effectively facilitate collaborative approaches to planning and management can serve as integral components within the governance of coastal systems and their essential resources and services. Realistic, immersive $^{1}$ geographic visualizations, referred to here as "geovisualizations," their capacity to communicate management or development outcomes to diverse groups of stakeholders. Through realistic representation, geovisualizations can provide people of a variety of different backgrounds and expertise with salient understanding of how they would feel about certain management outcomes or impacts if they transpired in real places (Sheppard, 2001; Newell and Canessa, 2015). In turn, this can enable productive planning discussions among different parties that are potentially affected by proposals and plans. In support of this notion, previous research has found that these types of geovisualization show promise as tools for collaborative efforts such as climate adaptation planning (Sheppard et al., 2011), understanding and assessing natural resource management options (Lewis and Sheppard, 2006), and stimulating land-use planning discussions among stakeholders (Schroth et al., 2011).

Although research has made progress elucidating the potential geovisualizations have as tools for collaborative planning and management, this work has primarily been conducted in the terrestrial context (e.g., Tress and Tress, 2003; Lewis and Sheppard, 2006; Schroth et al., 2009, 2011; Smith et al., 2012), leaving the coastal context largely unexplored. Coastal systems have particular biophysical and human-related characteristics that present unique challenges and considerations for geovisualization work, and these are insufficiently understood through terrestrial-focused research. Coasts consist of a land-tosea continuum; thus, they are geometrically complex and support a wide variety of activities, interests and values (Thompson, 2007; Shackeroff et al., 2009; Stocker and Kennedy, 2009). Engaging in effective coastal management and governance requires recognition that these places comprise interdependent marine and terrestrial environments (Cicin-Sain, 1993; Garriga and Losada, 2010), tasking coastal geovisualization with the challenge of capturing such complexity. In addition, coastal systems act as the nexus between terrestrial and marine processes and thus form highly dynamic places (Sorensen, 1997). Therefore, unlike terrestrial visualizations, which can be constructed as

\footnotetext{
${ }^{1}$ The term "immersive" often refers to devices used to display visualizations, e.g., virtual reality headset (Lovett et al., 2015); however, it can also relate to method of interaction. For example, first-person perspective navigation (such as done with the geovisualization featured in this study) can contributes to immersion (Isaacs et al., 2011).

${ }^{2}$ This paper employs the term, "geovisualization," to refer specifically to digital representations of real-world places that are geographically-accurate and built with high degrees of realism. Other research might refer to these as "landscape visualizations" (Lewis and Sheppard, 2006) or "3D visualizations" (Grêt-Regamey et al., 2013).
}

static images (e.g., Tress and Tress, 2003; Lewis and Sheppard, 2006; Schroth et al., 2009), coastal geovisualizations must incorporate dynamic, four-dimensional properties in order to accurately capture the "reality" of coastal places (Gold et al., 2004; Beegle-Krause et al., 2009). In recognition of these considerations, Newell and Canessa (2017) recommend building coastal geovisualizations with navigability to allow for movement across the land-sea interface and also with fourdimensional properties in order to convey dynamism. Building geovisualizations (and virtual representations of scenarios) with such properties presents challenges; however, addressing these challenges is necessary for these tools to be effective for collaborative planning within the coastal context.

This work is part of a larger research project, which explores geovisualizations as tools for collaborative coastal management and planning, and the current paper details the second part of this two-part study. The first part involved building the coastal geovisualization and examining how well it represents a realworld coastal place (Newell et al., 2017). This paper focuses on building coastal management scenarios into the geovisualization and then investigating how the tool performs in terms of allowing diverse groups the ability to effectively assess scenarios and provide thoughts, comments and ideas.

\section{METHODS}

\section{Study Area}

The geovisualization in this study models the Sidney Spit area in the Gulf Islands National Park Reserve (GINPR), which comprises the northern most portion of Sidney Island and is located $\sim 4 \mathrm{~km}$ east of the municipality of Sidney, BC (Figure 1). The park contains a spit that projects $1.8 \mathrm{~km}$ northward (known as Long Spit) and is contiguous with hook-shaped spit (known as Hook Spit) that forms the border of a lagoon. Sidney Island provides critical habitat for a variety of bird species and marine life, and the northern part of the island and adjacent waters were established as the Sidney Spit Provincial Marine Park in 1961 (Maurer, 1989). In 2003, this area became incorporated within GINPR, and current uses of the space consist primarily of recreational activities such as camping and walking (Parks Canada, 2012). The island is accessible by private boat or by a seasonal ferry, which typically runs from late-May to earlySeptember (Parks Canada, 2012). Marine areas around the island are used by boaters, and some fishing activities are permitted in these spaces (Fisheries and Oceans Canada, 2014).

\section{Sidney Spit Geovisualization}

The geovisualization was developed using data provided by Parks Canada and collected through fieldwork. The process involved a combination of ArcGIS (v10.3.1), Adobe Photoshop (CS5), Trimble SketchUp (pro 2015) and Unity3D (v5.3.4) game engine. These programs were selected respectively to build the model with spatial integrity (ArcGIS), develop realistic textures (Photoshop), build objects (SketchUp) and create a dynamic and navigable virtual environment (Unity). The result was a representation of Sidney Spit that allowed users to walk through it, experience it from the first-person perspective, and interact 

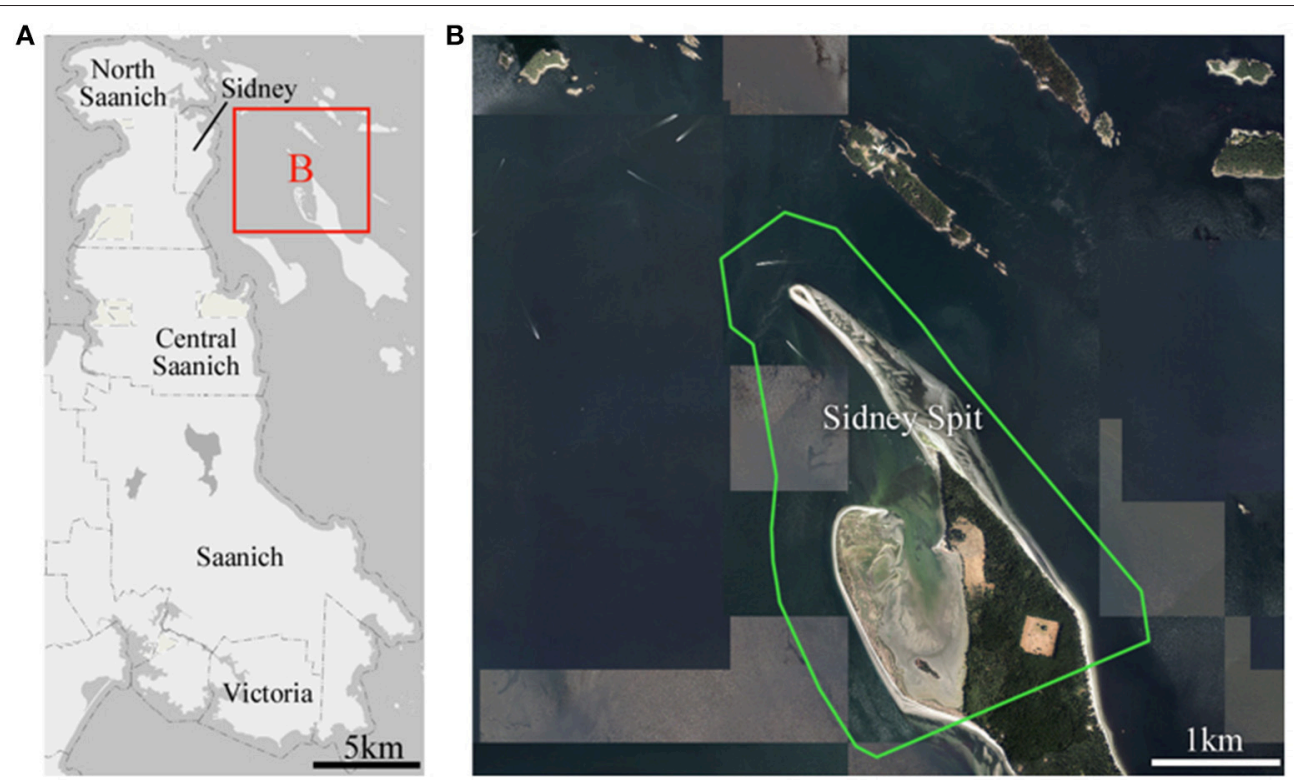

FIGURE 1 | Map of Sidney Spit and surrounding area. Base maps were retrieved from the Capital Regional District Regional Map system. (A) Features a map of municipalities near Sidney Island. (B) Features a map of Sidney Spit Park (park boundaries are displayed in green).

with a variety of static and animated elements, such as signs, litter, picnic tables, beached dinghy, a dock, fences, the lighthouse, pilings, boats, crabs (Dungeness), dogs, gulls, people, vegetation (marine and terrestrial), and driftwood. A complete description of the modeling process can be found in Newell et al. (2017).

The geovisualization contains $\sim 85$ hectares of navigable area, spanning from the main dock to north of the Long Spit, and bounded by an impassible invisible barrier (Figure 2). The geovisualization loads with the user at the dock, and the users can "walk" through the virtual environment at a pace of $10 \mathrm{~km}$ per hour. The travel pace is faster than typical walking speed; however, it was selected because people generally perceive their movements in virtual environments as slower than the actual speed the camera travels (Bishop and Rohrmann, 2003). As shown in Figure 2, a user can also travel through geovisualization using key commands that relocates him or her to various "teleportation points." This feature was added to allow users to explore different parts of the spit and examine key areas affected by the scenarios without spending excessive time "walking." Teleportation points initially were distributed evenly along the spit. However, points were added and repositioned to locations near areas where effects of scenarios could be observed (see sections on geovisualizations scenarios below).

Modeled elements located outside the boundaries of the navigable area formed the viewshed. Nearby elements (i.e., within $\sim 3 \mathrm{~km}$ of navigable area) were modeled three-dimensionally and in a similar manner to those within the navigable space. However, more distant elements were represented through a "skybox," which is a cube constructed around a virtual environment equipped with images on the inside panels to serve as background scenery (e.g., Hong-ge, 2010; Hu et al., 2012). Skybox panels were aligned in a manner that panel imagery displayed similar views to what park visitors would see when in various locations within the park (Figure 3). It is worth noting that these views were only visible above the water surface, as a fog effect was applied in the underwater areas of the geovisualization to represent the lower visibility experienced in marine environments (Figure 3), similar to that done in Canessa et al. (2015).

The majority of geovisualization work has focused on the visual sense, while there is recognition around the value of developing multisensory tools for planning (Lindquist and Lange, 2014); and accordingly, this geovisualization incorporates auditory stimuli. Sounds within the geovisualization include ocean waves, boat motors, gulls cawing, dogs barking, people walking on the beach, greetings from other park visitors, and sounds of conversation. Most sounds were associated with particular objects and could be experienced three-dimensionally (i.e., stereophonic sounds that change in volume depending on distance to source). Ambient sounds were also included, consisting of ocean waves when above the water surface and "bubbling" when below the surface. Many sounds were triggered by "colliders," meaning that the sounds were activated when entering a particular space; for example, greetings would sound when entering a collider positioned in front of a model person.

\section{Developing Geovisualization Scenarios}

Scenarios were developed around management issues that are faced by the park. The issues were selected following a focus group comprised of six Parks Canada staff, including those working in resource management, promotion, protection, visitor experience, and interpretation. The group was affiliated with the Parks Canada branch responsible for the management of Sidney Spit; thus, they were able to comment on critical issues and considerations specifically associated with the park. 


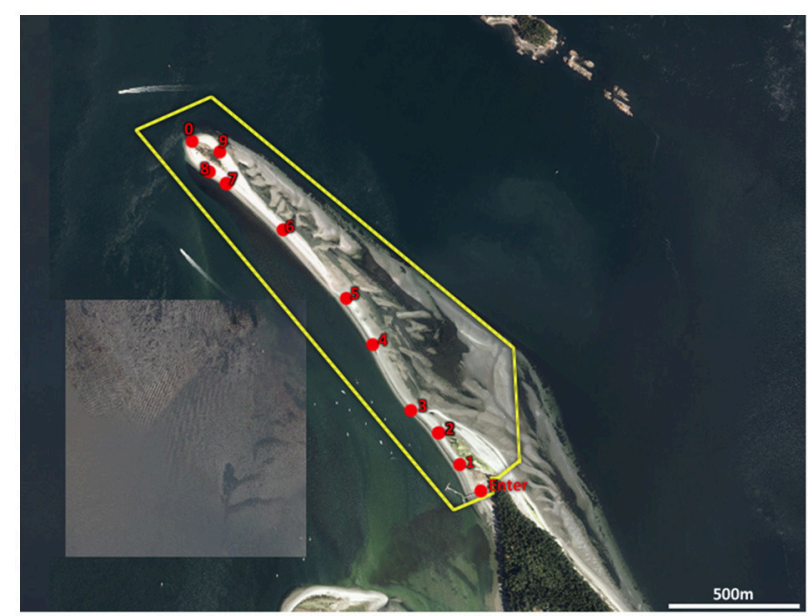

FIGURE 2 | Map representing the geovisualization's navigable area. The yellow lines demarcate the boundaries of the navigable area of the Sidney Spit geovisualization. Red makers represent teleportation points, and marker labels display key commands for teleporting to the respective locations.

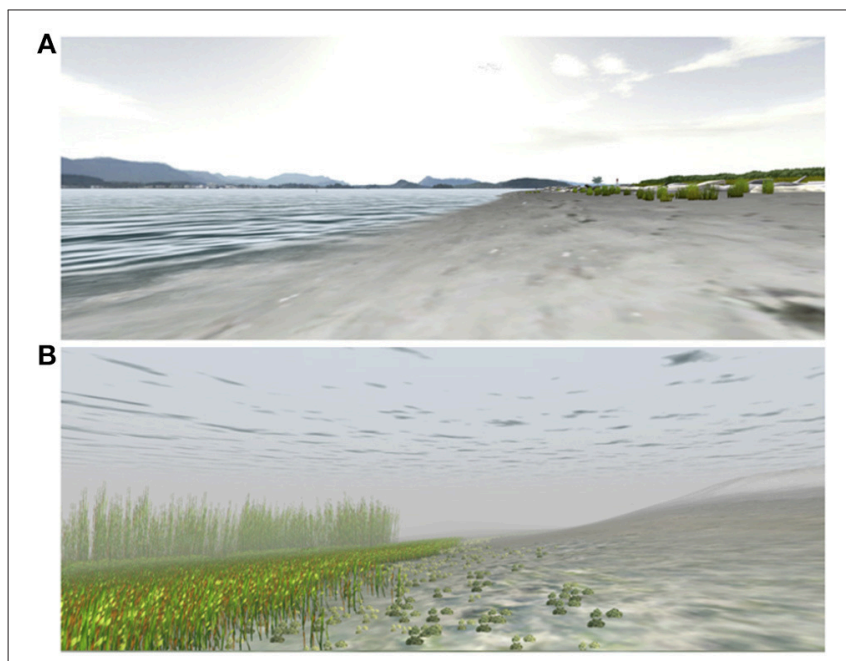

FIGURE 3 | Geovisualization views from above and below water surface. (A) Displays a screenshot of the geovisualization with the user located above water and on the beach. (B) Displays a screenshot of the user located underwater.

The session was held at the Parks Canada office in Sidney, BC, and lasted $2 \mathrm{~h}$. The session began with a 15-min presentation on how the geovisualization was built. The geovisualization was then presented on a 50-inch Panasonic TH-50PH12 screen, running the application from a Dell Precision T1700 computer with an NVidia Quadro K2200 graphics card and external speakers for sound. The group was given a demonstration on how to navigate the geovisualization and what terrestrial and marine elements can be seen within the virtual environment. Following the demonstration, a discussion was held on potential applications of the geovisualization and the types of issues it can be used for as a communication tool. The group also commented on what elements contributed to and detracted from the geovisualization's realism and representation of a real-world place; however, results from that discussion are reported in Newell et al. (2017).

Several suggestions were made around potential applications for the geovisualization, and three particular management issues were selected for the purposes of this study. The selection was based on how prevalent the management issues were within the focus group discussion and the potential for clearly representing different management options around the issues using the geovisualization. The resulting scenarios presented options for (1) fencing of a vegetation restoration area, (2) positioning of mooring buoys for use of recreational boaters, and (3) managing of dog activity within the park.

\section{Fencing}

Fencing scenarios were based on potential plans for removing Scotch broom located in the northern portion of Sidney Spit and allowing native plants to spread throughout the area. Scenarios were developed with the intention of discouraging people from entering the vegetation area, while also minimizing the amount of fencing required to achieve said objective. Parks Canada identified two potential configurations for fences, each requiring $\sim 215 \mathrm{~m}$ of fencing (Figure 4). One option involved fencing only part of the vegetation area with a full enclosure loop encompassing the northern half. This configuration does not capture the entire area but it would protect certain critical species concentrated in the northern portion, particularly contorted-pod evening primrose (Camissonia contorta). The second configuration spans more of the vegetation area using the same length of fence by only covering the southern and western sides of the area. The effectiveness of this configuration is based on the fence serving more as a signal for people not to enter the area, rather than being an actual physical barrier. The majority of visitors are entering the park from the main dock, and (based on field observations) most appear to approach the north end of the spit walking along the west beach; thus, these visitors would encounter the south and west fence in their walks. In addition, it was noted through the Parks Canada focus group that the eastern side of the vegetation area is steeper when approaching from the beach, which could serve to discourage people from entering the vegetation area when on the eastern beach.

Fencing scenarios also included options for potential locations for signs to be placed along the fence. Potential sign locations were selected by the researcher (i.e., rather than Parks Canada), and locations differed depending on configuration. Locations identified for the west side only option included a southern position, a northern position and a "mid-way" position (Figure 4A). Locations identified for the full enclosure option included a point on the west side, a point on the east and a point near the lighthouse at the northern end (Figure 4B). The design of signs remained the same for all locations and both configurations, consisting of a square board bolted to a wood post with a simple message directing people to stay out of the restoration area (Figure 5).

Fencing scenarios also involved options for materials and design, and these included split-rail wood fencing, rope fencing supported by wooden posts, and wire mesh fencing (Figure 5). 

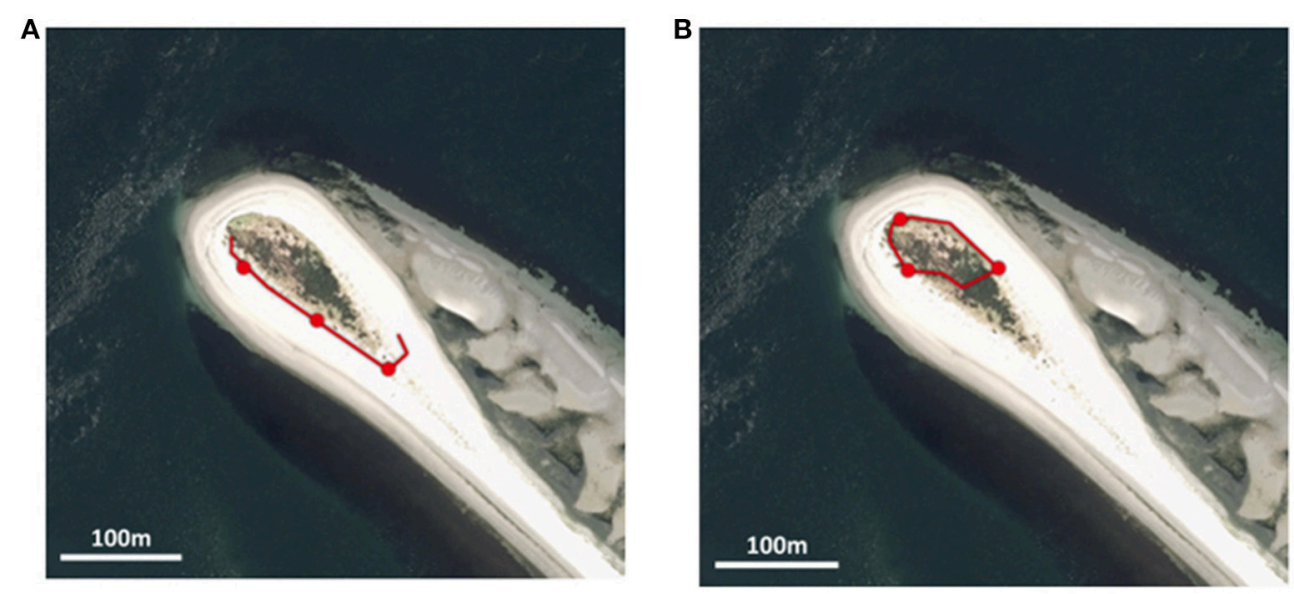

FIGURE 4 | Maps of fencing configurations and potential sign locations. (A) Displays the west side only configuration. (B) Displays the full enclosure configuration. Red markers identify potential sign locations.

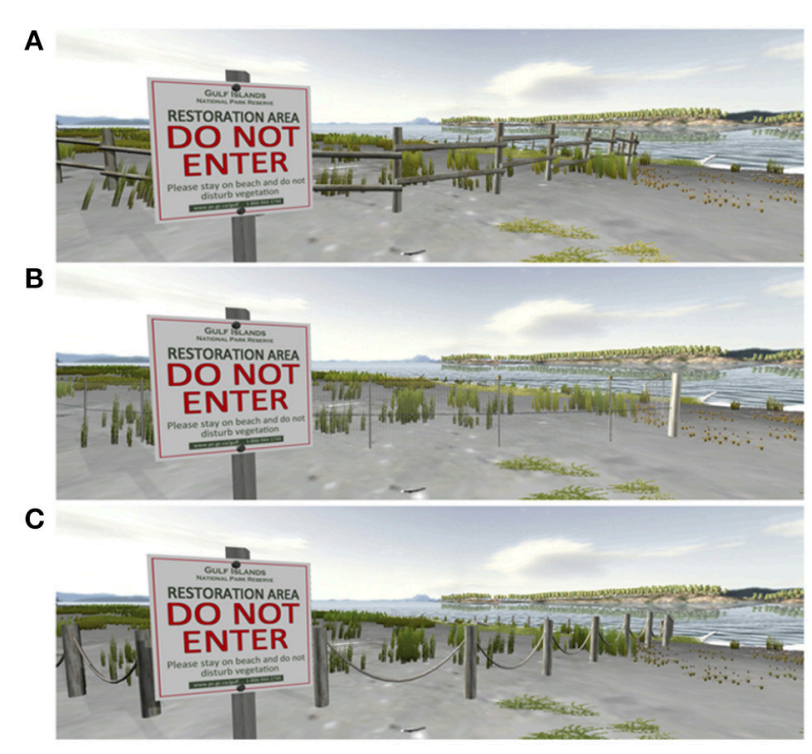

FIGURE 5 | Fencing scenario materials and designs. (A) Exhibits the split-rail wood fencing option. (B) Shows the wire meshing fencing option. (C) Displays the rope fencing option. As seen in the images, wording, and design for fencing signage is consistent among all three fencing types.

The former two were selected because they aesthetically align with fencing already present within the park (i.e., split-rail) and the nearby town of Sidney (i.e., rope). The selection of the latter was based on other coastal dune fencing projects that have employed wire mesh (e.g., Devoy, 2016).

Previous visualization research has linked metrics such as financial costs with visualized scenarios to allow users to make more informed decisions (Grêt-Regamey et al., 2013), and drawing from this research, expenses associated with constructing fences (i.e., materials and labor) were estimated for each of the three fencing types. This was done by consulting a variety of websites that provide information on potential costs of construction projects, such as fencepriceguides.com, homewyse.com, promatcher.com, rnmfencing.com, angieslist.com, homedepot.ca and costhelper.com. Costs (in Canadian dollars) were estimated to be $\$ 20,000$ for split-rail, $\$ 3,500$ for wire, and $\$ 17,500$ for rope. It is important to note that these figures represent very rough estimations and were not considered reliable for actually budgeting and executing fence construction. However, they capture differences in the magnitude of costs, and in the context of the current study, this was considered sufficient for assessing how well the geovisualization performs as a planning tool.

Positioning of fences and signs was done using what this research refers to as "reference maps," which are maps that are imported in Unity and fitted onto terrain assets in order to guide spatially accurate placement of objects (Newell et al., 2017). Reference maps for the fencing configurations were prepared from digitized images of orthophotographs with pen-drawn lines on them (drawn by Parks Canada staff). Reference maps for sign locations were prepared by adding points to the maps in Photoshop after digitization.

Once fencing scenarios were built in Unity, key commands were assigned to toggle different configurations, materials, and sign locations. Key commands were assigned in such a manner that single key would toggle both a certain configuration and particular material, resulting in six keys allocated for toggling the three materials in both configurations. Once a particular configuration was selected, three other keys could be used to position the signs in one of the three proposed signage locations. Fencing scenarios could also be toggled off by a key command that disables fence and sign models.

Since fencing scenarios were based on plans for removing Scotch broom and allowing native plants to spread throughout the area, toggling fencing scenarios reflects this change by displaying different types and compositions of plant elements. Toggling replaces Scotch broom elements with native plant elements, namely contorted-pod evening-primrose (C. contorta), 


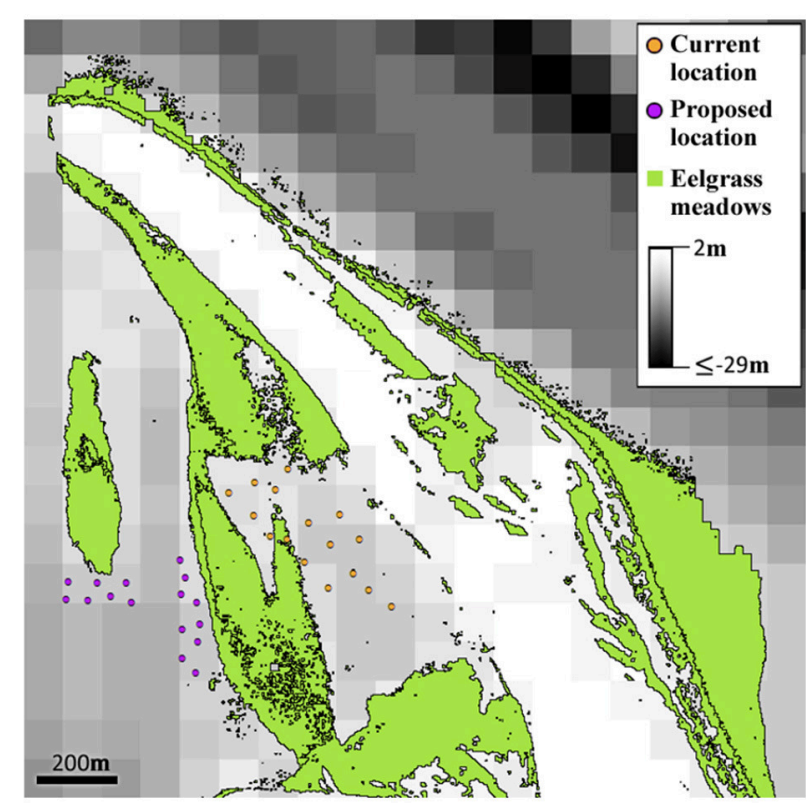

FIGURE 6 | Map of eelgrass and mooring buoy scenarios. Current mooring buoy locations are represented through orange markers, and proposed locations for the relocation scenario are represented through purple markers. Eelgrass maps were created using data collected by O'Neill et al. (2011).

yellow-sand verbena (Abronia latifolia), silky beach pea (Lathyrus littoralis) and dune grasses. Following a suggestion made during the Parks Canada focus group, the composition and density of the native vegetation were modeled using images of a plant restoration site located on a nearby island (James Island) with similar native species, retrieved from websites (COSEWIC, 2009; NCC, 2015) accessed in the spring of 2016. Modeling of contorted-pod evening-primrose patches was also guided by reference maps prepared from Parks Canada "species at risk" maps that display current distributions of the plant.

\section{Mooring Buoys}

Mooring buoy scenarios were developed based on concerns frequently expressed in the Parks Canada focus group regarding potential damages to eelgrass meadows from boat anchoring. Mooring buoys are currently available off the west side of Sidney Spit for the use of recreational boaters, and these buoys allow for moorage without need for boat anchors. Only 16 buoys were present at the time of the scenario development (spring/summer of 2016), and a concern exists that boaters will drop their anchors in adjacent areas where eelgrass meadows are present when buoys are unavailable (or if they are unaware of the mooring buoy system). To mitigate against such issues, a potential relocation of mooring buoys was designed in such a manner that would position the buoys outside of the eelgrass meadows, thereby reducing likelihood of anchoring within the meadows. This scenario also includes regulatory marker buoys that are positioned between mooring buoys and eelgrass meadows, which indicate that mooring is not permitted past the marker.
The "proposed relocation" scenario was developed using data obtained from Parks Canada, which consisted of eelgrass meadow polygons created from remote sensing data (O’Neill et al., 2011), multibeam bathymetry raster data $(100 \mathrm{~m})$, and point data representing the current buoy locations. The first step in developing the scenarios was to determine a minimum distance between mooring buoys, which would ensure that the relocation was not significantly more "crowded" than the current location. This was done by using ArcMap and involved calculating the minimum distance observed between buoys in the current distribution $(43.3 \mathrm{~m})$. The next step involved minimizing increases in mooring system installment depths and chain lengths (increases were expected to occur because the relocation is in a deeper area than the current mooring area). This was done by defining an area located outside of the eelgrass meadows, which encompassed raster cells of shallower depths. Once this area was defined, 16 buoys with a minimum spacing of $43.3 \mathrm{~m}$ were randomly distributed within the area using ArcMap (Figure 6).

Despite efforts to minimize increases in crowding, boats in the proposed relocation scenario ultimately were on average nearer to one another than those in the current location, as evidenced by an independent sample $t$-test using values of distances between nearest points $\left[t_{(30)}=5.88, p<0.001\right]$. Boats in the current location assumed a mean distance of $65.1 \mathrm{~m}(S D=11.6)$, while the proposed relocation assumed a mean distance of $47.6 \mathrm{~m}$ $(S D=2.79)$. In addition, mean depths at current buoy locations $(M=3.04, S D=1.09)$ and proposed relocation points $(M=4.07$, $S D=0.97)$ were also found to be different with the latter being significantly deeper $\left[t_{(30)}=2.81, S D=0.01\right]$. The proposed relocation would require $34 \%$ more chain than what is currently used (i.e., sum total depth of current location is $48.7 \mathrm{~m}$, where sum total depth of relocation is $65.1 \mathrm{~m}$ ). Therefore, albeit efforts were made to maintain comparable spacing and depths between the current mooring buoy locations and the proposed relocation, ultimately the scenarios were found to differ in these ways.

The current locations of mooring buoys were built into the geovisualization by using a reference map prepared from point data of buoy locations and then placing boat models above all 16 points in vertical alignment with the water surface (Newell et al., 2017). Four additional boats were placed within the vicinity of the mooring buoys, which represented boats using anchors rather than buoys ${ }^{3}$. The proposed relocation scenario was built into the geovisualization using a reference map prepared from the relocation points that was developed using ArcMap (as described above). In a similar manner to that of the current location scenario, four additional boats were added within the area. As noted above, relocation scenarios also involved regulatory markers, and eight of these markers were positioned between the buoys and eelgrass meadows.

Key commands were assigned to toggle different mooring buoy scenarios, and users could experience the scenarios from land or from aboard a moored boat. Experiencing scenarios on

\footnotetext{
${ }^{3}$ Parks Canada has provided 16 mooring buoys; however, field data indicates that more than 16 boats are generally observed in the area, as field counts averaged to 20 boats (Newell et al., 2017). This indicates that some boaters are (likely) using their anchors within the area, which is represented in the geovisualization.
} 
land involved using key commands to toggle the different boat positions, allowing users to assess how these positions might affect the views when standing within the park (Figures 7A,B). Experiencing scenarios on water involved using key commands to transport users to the deck of moored boats, allowing users to interact with the scenarios from a boater's perspective (Figures 7C,D). The boats that users board when experiencing scenarios from this perspective are located $\sim 200 \mathrm{~m}$ (i.e., current location) and $500 \mathrm{~m}$ (i.e., proposed relocation) away from the Sidney Spit shoreline.

Recreational boaters mooring near Sidney Spit can enter the park using their privately owned dinghy, and the geovisualization captures how the proposed relocation might affect this method of access. When aboard a boat in the geovisualization, users can step off the starboard side of the boat to land on a dinghy model and activate an animation where dinghy and user travel to shore. Dinghies travel at seven knots in both current location and proposed relocation scenarios, giving users a sense of the differences in travel times between the two scenarios (i.e., $55 \mathrm{~s}$ in the current location and $140 \mathrm{~s}$ in the proposed relocation).

\section{Dog Management}

Dog management scenarios were developed based on concerns expressed through the Parks Canada focus group regarding offleash dogs. Sidney Spit provides important habitat for a variety of wildlife, particularly bird species (Maurer, 1989), and offleash dogs can be a significant source of disturbance to such wildlife (Lafferty, 2001; Antos et al., 2007; Williams et al., 2009). Current park regulations dictate that dogs must be on-leash at all times in the park. However, visitors do not always comply with these regulations, presenting risks to local wildlife. In recognition of these risks, three scenarios were prepared: one that depicts no change to the current situation, a regulation that prohibits bringing dogs to the park, and efforts to increase compliance among park visitors of the on-leash regulations.

The "current situation" scenario was built with two dog models featured in the geovisualization. One of the models was placed at the southern end of the spit, and it was featured with another model representing a dog owner. These models were animated to depict an owner walking a dog while onleash (Figure 8A). The other dog model was placed toward the northern end of the spit and was also associated with an owner model; however, this model pair was depicted without a leash. The off-leash dog was animated to appear to run northward and toward a colony of gulls (Figure 8B). The gull models were animated to appear to fly away when the dog reaches the colony. The two model pairs represent different dog and owner behaviors, and they were both incorporated into geovisualization to convey that some dog owners comply with the on-leash regulation, whereas others do not. It is worth noting that the
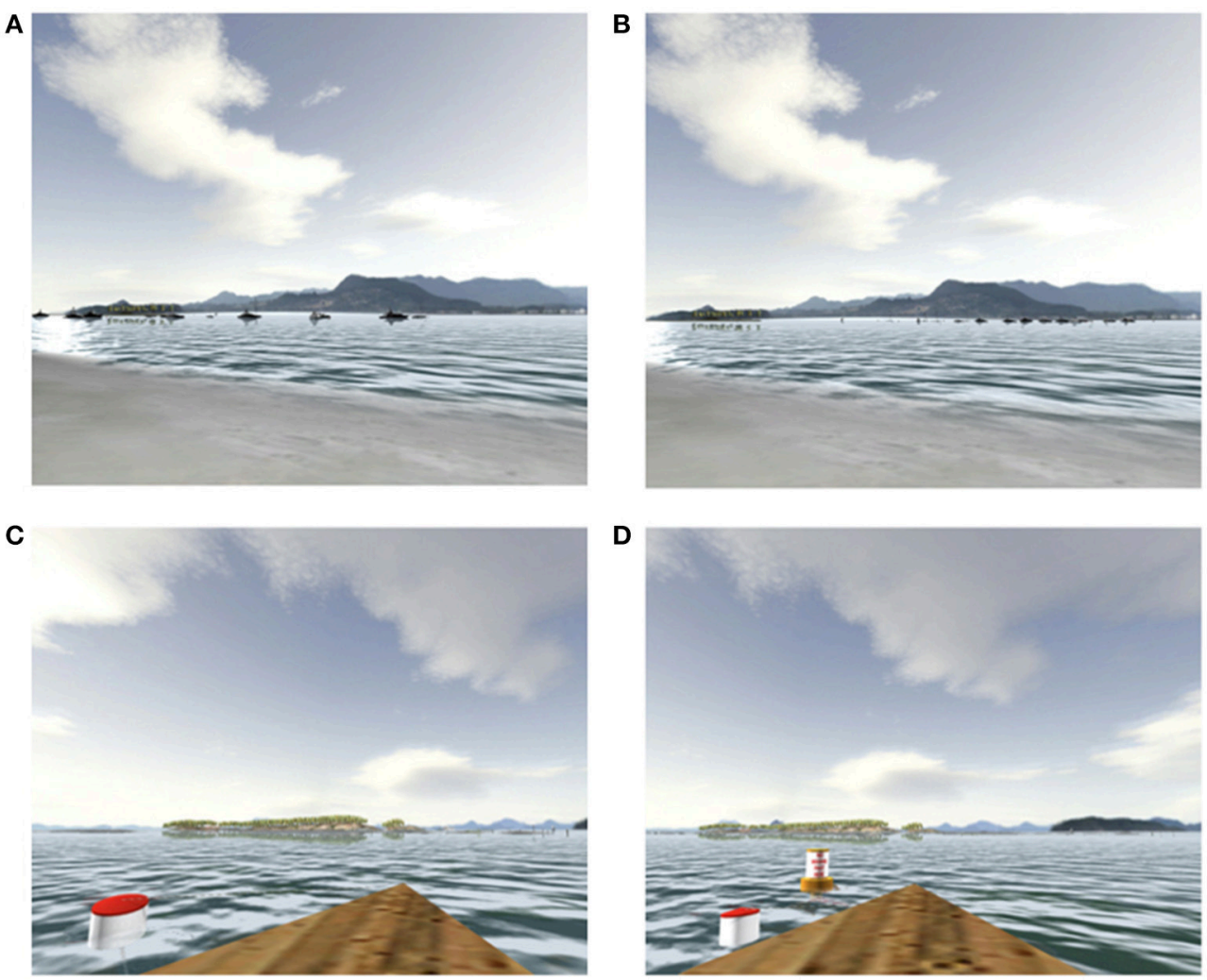

FIGURE 7 | Mooring buoy scenarios experienced from land and from aboard boats. (A) Displays view of moored boats in the current location scenario as seen from land, and (B) displays view of moored boats in the proposed relocation scenario (also as seen from land). (C) Displays a view from aboard a boat in the current location scenario, and (D) displays a view from aboard a boat in the proposed relocation scenario. Mooring buoys can be seen in (C,D), and a regulatory marker buoy can be seen in (D). 

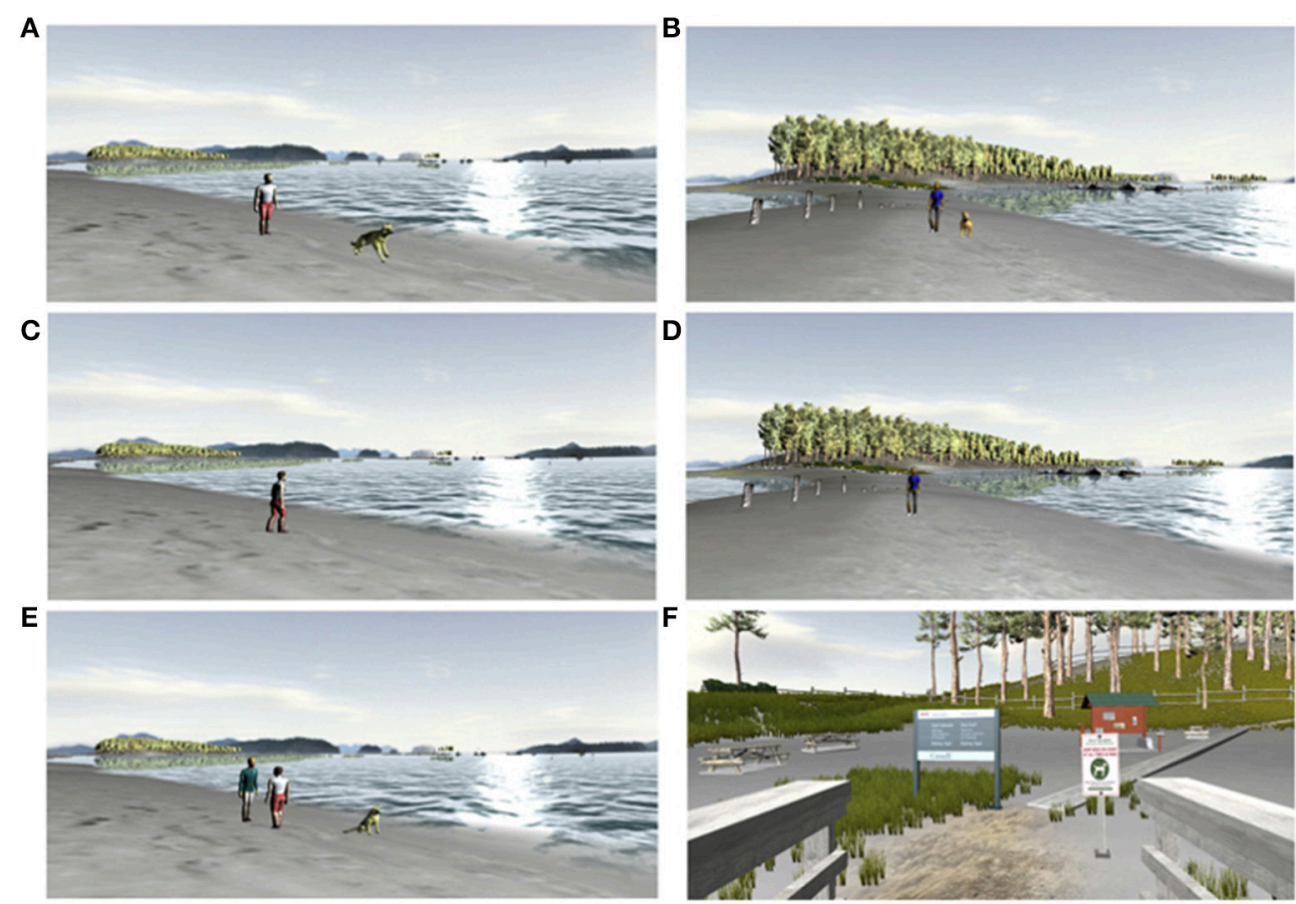

FIGURE 8 | Dog management scenarios. (A,B) Depict the current situation scenario. (A) Displays owner and off-leash dog located toward the north of the spit, and (B) displays owner and on-leash dog at the southern end of the spit. (C,D) Depict the no dog scenario, and display people without dogs at the northern and southern locations (respectively). (E,F) Depict the increased awareness scenario. (E) Displays a Parks Canada staff talking to the dog owner at the northern location with the dog now leashed. (F) Displays a sign placed near the dock reminding visitors of the dog leash regulations.

placement of the off-leash dog was not (entirely) arbitrary, as it was based on an interaction between gulls and an off-leash dog observed during fieldwork.

The "no dog" scenario was constructed to simply consist of no dog models in the geovisualization. Similar to other scenarios, the no dog scenario was toggled using a key command. Toggling the scenario resulted in the on-leash owner depicted as walking in the park by herself (Figure 8C) and the off-leash owner depicted as viewing the ocean rather than watching his dog (Figure 8D).

The "increased awareness" involved the addition of three models to the geovisualization-two representing Parks Canada employees (Figure 8E) and another representing a sign (located by the dock) that communicates the dog leash regulation to visitors entering the park (Figure 8F). One of the Parks Canada models was positioned near the dog and owner at the northern location, and the models were animated in a manner that depicted Parks Canada staff talking to the owner while the dog was now leashed. A sound clip was triggered when approaching the models, which consisted of a male voice explaining the onleash regulation and the importance of complying. The second Parks Canada model was positioned at the southern end of the spit and was depicted as a staff member, who was watching park visitors to ensure people are complying with on-leash regulations. Approaching this model triggered a sound clip, consisting of a female voice reminding people of the on-leash regulation. An additional sound clip was activated when the owner-dog pair at the southern end of the spit moved within proximity of the
Parks Canada model, and this clip consisted of the female voice thanking the dog owner for complying with the regulation.

Similar to fencing scenarios, expenses associated with Parks Canada staff time were roughly estimated to be able to associate cost metrics with this scenario. It was deemed feasible that the job could be assigned to summer students because the tasks require a relatively low level of expertise, and the park receives the majority of visitors in the summer. Parks Canada student pay rates were thus used to estimate costs (Parks Canada, 2014). Based on a 7.5h workday, costs for two students were estimated to be around $\$ 190$ to $\$ 200$ per day.

\section{Focus Groups}

Focus group methodology was used to examine how well the geovisualization performs in terms of allowing people to assess and provide thoughts on scenarios. In total, 27 participants were recruited for the study. Age distribution of participants consisted of $63.0 \%$ over the age of $65,29.6 \%$ aged $55-65$, and $3.7 \%$ aged $45-$ 54 (the remaining $3.7 \%$ was non-response). Gender distribution consisted of $70.4 \%$ female and $29.6 \%$ male. All participants resided within the Capital Regional District (BC, Canada) and median length of residence was 24 years with the maximum being 70 years and the minimum being 2 years.

Recruitment was done through letter mail, and an invitation was sent to a random sample of 300 addresses. Recruitment initially targeted the municipalities of Sidney and North Saanich, as they are nearest to Sidney Spit, thus allowing the study to 
follow methodology of other visualization research that examines responses of local residents (e.g., Lewis and Sheppard, 2006; Salter et al., 2009; Schroth et al., 2009). However, further recruitment was needed for the study, and this was done through snowball sampling ${ }^{4}$, which resulted in participants from other nearby municipalities. Ultimately, Sidney and North Saanich residents collectively comprised the majority of the participants (respectively 44.4 and $22.2 \%$ ), but some of the participants resided in other municipalities, including Saanich (18.5\%), Victoria (11.1\%), and View Royal (3.7\%).

Focus groups were conducted over seven sessions during July and August of 2016, and were held either in a conference room at the Mary Winspear Centre (Sidney, BC) or in the GIS Visualization Lab at the University of Victoria. Groups ranged in size, consisting of (listed chronologically) seven, eight, two, two, two, and five participants, as well as separate session involving one participant ${ }^{5}$. Focus groups sessions were $2 \mathrm{~h}$ in length; however, this paper reports on only part of the session and the other parts are discussed in Newell et al. (2017). Similar to the Parks Canada session, the geovisualization was demonstrated using a Dell Precision T1700 (displayed by projecting onto a screen) with external speakers for sound. Each participant was also provided with a Lenovo ThinkPad T530 laptop (and headphones) equipped with the geovisualization and an information booklet detailing user controls, which allowed participants to explore the geovisualization on their own.

For each of the three scenario types, focus group participants were given a brief presentation on the rationale behind scenarios and a demonstration on toggling scenario options. Participants were also provided with supplementary information to enhance their understanding on the scenarios, such as maps (i.e., Figures 4, 6) and cost estimates (see Fencing and Dog Management). Participants were given time to explore scenarios on the laptops, as well as through the screen projection by asking the session facilitator (i.e., researcher) to display particular options. During this time, participants provided comments on preferences for scenario options and the geovisualization's usefulness for assisting with decisions around these preferences. Comments were provided through feedback forms and a brief discussion held at the end of the session, and data were analyzed using NVivo (v.10). Data were also collected through asking participants to rate the geovisualization's usefulness on a scale of 1 (i.e., "not at all") to 10 (i.e., "extremely well") in terms of how well it assisted with decisions, similar to those done in other visualization studies (e.g., Schroth et al., 2009; Smith et al., 2012). After all scenarios were explored, participants were asked to rate (on a scale from 1 to 10) and comment on the user-friendliness of the geovisualization, as well as provide feedback on how essential

\footnotetext{
${ }^{4}$ Snowball sampling consisted of recommendations from recipients of invitation letters, both from people who accepted the invitation and those who were unable to attend focus groups. In addition, some recruitment was done through professional networks. In particular, a connection with the District of Saanich's free local parks walking program allowed for recruitment of participants of the walking program.

${ }^{5}$ The session with the singular participant was the only session held in August, and it consisted of a person who was scheduled for an earlier session but had to cancel due unexpected circumstances.
}

it was to have supplementary information (i.e., maps and cost estimates) to use the tool.

Geovisualization studies often involve the participation of people who reside or have personal familiarity with a visualized locality (e.g., Lewis and Sheppard, 2006; Salter et al., 2009; Schroth et al., 2009), and Newell and Canessa (2015) posited that such familiarity can enhance the geovisualization's ability to connect with people's values, beliefs, and interests associated with the real-world places depicted through the visuals. In the current study, however, the visualized place was located a ferry ride away from the participants' homes, and it could not be assumed that all participants were familiar with the physical location. This provided an opportunity to investigate familiarity effects and their influence on user interactions with geovisualizations. Familiarity effects were investigated using two approaches. The first involved "priming" some of the participants by taking certain groups out to Sidney Spit prior to exploring the geovisualization (groups $n=7, n=8$ and $n=1$ ), while another group served as a control by either visiting the park afterward (group $n=5$ ) or not at all (groups $n=2, n=2$ and $n=2$ ). The second approach involved asking participants how many times they have visited Sidney Spit prior to the session (i.e., excluding the trip taken on the day of the session), and responses from those who had visited only once or not at all were classified as "unfamiliar" and those who have visited multiple times in the past were classified as "familiar". More detail on the approaches for characterizing familiarity can be seen in Newell et al. (2017).

As this research involved human participants, an ethical review was conducted and approved by the Human Research Ethics Board of the University of Victoria. Focus group participants were provided with a letter of informed consent that contained information on the research and their participation, and they signed these letters prior to engaging in the research. Signed copies were kept by the researcher, and participants were provided with unsigned copies for their reference. In accordance with the ethical review, names of individuals are not displayed in this paper, and references to particular participants are done using identification numbers.

\section{RESULTS}

\section{Fencing Materials}

Table 1 displays participant preferences for fencing materials in terms of ranking them from most to least preferred. Top rankings consisted of $44.4 \%$ selecting mesh, $29.6 \%$ selecting wood, and $18.5 \%$ selecting rope ( $7.5 \%$ did not respond). Mesh was ranked

TABLE 1 | Percentages of participants indicating preferences for different fencing materials.

\begin{tabular}{lcccc}
\hline Preference & \multicolumn{3}{c}{ Material } & No response \\
\cline { 2 - 4 } & \multicolumn{2}{c}{ Mesh } & Wood & Rope \\
\hline First & $44.4 \%(n=12)$ & $29.6 \%(n=8)$ & $18.5 \%(n=5)$ & $7.5 \%(n=2)$ \\
Second & $7.5 \%(n=2)$ & $48.1 \%(n=13)$ & $25.9 \%(n=7)$ & $18.5 \%(n=5)$ \\
Third & $37.0 \%(n=10)$ & $7.5 \%(n=2)$ & $37.0 \%(n=10)$ & $18.5 \%(n=5)$
\end{tabular}


highest by more participants than other material but it was also commonly ranked as least preferred (37.0\%). Similar lowranking trends were observed with rope, as $37.0 \%$ selected it as least preferred, whereas a minority $(7.5 \%)$ selected wood as last preference (18.6\% did not response). For second preferences, wood was most frequently noted (48.1\%), followed by rope (25.9\%), and lastly mesh (7.5\%) (18.6\% no response).

Preferences for mesh were strongly divided among the participants, and reasons for this division were elucidated through comments provided in feedback forms and group discussions. Participants indicated preferences to be based on either aesthetics or functionality, and in some cases, this was regarded as a trade-off. In terms of functionality, mesh was viewed as most likely to be effective for keeping people out of the vegetation, as it is most difficult to get through and extends to the ground. Nevertheless, mesh was also ranked lowest by many, and this was primarily based on aesthetics. Even among those who ranked mesh highest, there were some who noted that aesthetics was a weakness of this option.

"Mesh would be the most effective. Is also the least attractive." (Participant 6)

In contrast to mesh, wood was considered to be quite aesthetically appealing. Comments around wood fencing typically referred to how this style aligns better with the surroundings and natural environment. However, functionality and ability to prevent people from entering the restoration areas was generally not considered a particular strength of the wood option, and in some cases, participants who ranked wood highest also noted that mesh might actually make for a better barrier.

"Wood-natural, fits other 'wood' environment." (Participant 20)

"Wood looks best and fits with environment; Mesh—-makes actual barrier." (Participant 12)

Similar to wood, positive comments around rope fencing primarily related to aesthetics, and shortcomings related to functionality (or lack thereof). Feedback on rope aesthetics was more mixed than wood with some participants disliking its appearance. In addition, some participants were particularly critical of rope and its perceived lack of functionality, as comments were made during group discussions that rope might even attract people to sit on it or children to play with it. Other comments expressed how the look of rope does not present itself as a "real" barrier, thus implying that it does not adequately signal to park visitors for them to keep out of the restoration area.

"Rope-I don't like the look...or the potential effectiveness." (Participant 11)

"Rope won't do the job-not looking like a 'real' barrier." (Participant 13)

“Rope-Won't keep anyone out." (Participant 27)

As noted above, participants were provided with supplementary information regarding costs of different fencing options (see
Focus Groups), and some indicated that this information was taken into consideration when examining fencing scenarios. In these cases, cost information appeared to guide decisions toward mesh and away from wood or rope. However, cost benefits were ultimately expressed in conjunction with other factors, particularly aesthetics and functionality, and none of the comments indicated that expenses were the sole (or even primary) driver of decisions around scenarios.

"Mesh is most economical and offers the best protection-not very attractive, however... Wood looks best-fits in well with the natural setting-very expensive." (Participant 10)

"The mesh is a better price, more of a barrier than wood or rope, but doesn't look natural-it is actually quite unnatural looking...I like the look of wood the best-more natural and fits in better, but don't like the expense of it." (Participant 11)

Most negative comments concerning mesh related to its aesthetics. There were only some positive comments regarding mesh and visual appeal. The mesh itself was not considered by any to be particularly attractive, while some participants noted that it was harder to see than the other fencing materials. Therefore, as indicated by the participants, mesh could be a less visually intrusive option, and it might not even be visible from certain distances.

"Mesh fencing because from a distance (people in boats) will not see human development." (Participant 1)

“The mesh seems less visually intrusive." (Participant 17)

\section{Fencing Configuration}

The majority of participants selected the full enclosure scenario (70.3\%), whereas only $18.5 \%$ selected the west side only option (11.2\% did not respond). Reasons indicated for selecting full enclosure were similar to reasons for mesh, that is, the perceived level of protection offered by this option. Many participants felt that having a fence that only covers one side of the restoration area (i.e., west side only) was inadequate for protecting the vegetation, regardless of whether it spanned more of the area. Therefore, the rationale behind selecting full enclosure appeared to be that providing effective protection for some of the area was better than inadequate protection for the entire vegetation area.

"Full enclosure will ensure the plants will grow undisturbed." (Participant 1)

"Without enclosure, people will cross protection area." (Participant 12)

Some participants commented on how the full enclosure option offers better protection through how it "communicates" to park visitors. These comments referred to how a full enclosure configuration effectively signals to park visitors approaching the area from different angles that the area is sensitive and access is prohibited. This indicates that the perceived protective capacity was not simply based on how well the fence serves as a 
physical barrier; rather, it was also associated with its ability to communicate demarcation of restricted areas.

\footnotetext{
"More logical or intuitive when happening across it with no explanation-lots of people may come in on the [east] side and trample everything, not aware that they shouldn't be there." (Participant 22)

"Makes a statement-keep out/off...shows the seriousness of the project." (Participant 23)
}

Reasons for selecting the west side only fencing scenario varied. Some participants felt that west side only was adequate for discouraging people from entering the area, while holding the advantage of covering more area. Other participants mentioned that the west side only configuration was more visually pleasing. It is worth noting that these participants also selected wood as first preference for material, and this indicates that aesthetics played a strong role in their fencing scenario selections.

"Prefer open concept. More in keeping with natural area and pleasing to the eye." (Participant 14)

"Visually more satisfactory." (Participant 18)

\section{Signage}

Many participants selected preferences for sign locations based on perceived direction from where the majority of visitors approach the vegetation area (i.e., walking northward from the main dock). This resulted in $55.6 \%$ selecting the southern position in the west side only configuration, and 40.7 and $37.0 \%$ respectively selecting the western and eastern positions in the full enclosure configuration. It is important to note that participants appeared less certain of preferences for or partiality to a particular option for sign location than observed with any other aspect of the fencing scenario exercise. Several participants selected multiple sign locations for their preferences (22.2\% with west side only and $14.8 \%$ with full enclosure), and many did not respond with a particular preference (33.3\% with west side only and $29.6 \%$ with full enclosure).

In addition to assessing the proposed sign locations, other potential locations were explored using the geovisualization. An example of this involved the southwest corner of the full enclosure configuration. The western side of the full enclosure configuration extends into the vegetation area, and thus placing a sign right at the southwest corner could lead to visitors entering the area to read the sign (see Figure 4B). However, placing the sign on the southern edge could potentially be advantageous in that visitors approaching from the main dock would encounter the signage earlier than if placed further north. These considerations were recognized and brought forward in one of the focus groups, and subsequently, the geovisualization was used to determine if a sign could be placed in this area, while still being visible from the beach (i.e., without walking upon vegetation).

Participants also used the geovisualization to evaluate and comment on the appearance (design and wording) of the signs. Although this was not specifically asked for, this topic frequently emerged within focus groups. Some found the wording to be too "authoritarian" or "directive," and (thusly) felt it would not encourage cooperation from park visitors. During a group discussion, one participant alluded to having a negative visceral reaction to the wording by describing it as "offensive." These types of comments were followed by suggestions for "friendlier" language and interpretative signage that would explain the ecological importance of keeping people from entering the area.

"I would change wording on the sign-highlight restoration in progress and not such bold red letters of Do Not Enter. 'Please' would soften the message and feel more respectful to visitors." (Participant 11)

"Have sign asking people to respect the area under 're-vegetation.' Signs should explain what is happening and why and request they don't enter. Make the sign 'friendly."' (Participant 20)

\section{Mooring Buoys}

Participants were asked to indicate preferences for boating scenarios when experiencing scenarios from land and aboard the boats. As seen in Table 2, the majority of participants indicated preference for the proposed relocation scenario (59.2\%), while only $14.8 \%$ preferred the current scenario $(26.0 \%$ did not respond), when examining the scenarios from the land-based perspective. Preferences differed somewhat when examining the scenarios from the boater perspective, as $40.7 \%$ indicated preference for the proposed relocation and $33.3 \%$ preferred the current location (26.0\% did not respond).

Many of the participants who preferred the proposed relocation scenario noted the potential for protecting eelgrass meadows to be a reason for this preference. This was the case even among participants that did not initially have strong knowledge around the ecological importance of eelgrass. They gained knowledge from the researcher or other participants who explained this importance, thereby allowing them to make more informed decisions. In addition, participants mentioned that exploring the marine environment in the geovisualization prior to examining mooring buoy scenarios also helped provide an impression of the ecological significance of the eelgrass around Sidney Spit, as they encountered species that used eelgrass for habitat (i.e., Dungeness crabs, Cancer magister) and saw the extent of the meadows. It was noted during group discussions that such experiences provided a strong context for the mooring buoy scenarios and ultimately contributed to decisions toward strategies that might result in stronger eelgrass protection.

TABLE 2 | Percentages of participants indicating preferences for mooring buoy scenarios.

\begin{tabular}{llll}
\hline Perspective & \multicolumn{2}{c}{ Mooring buoy scenario } & \multirow{2}{*}{ No response } \\
\cline { 2 - 3 } & Current location & Proposed relocation & \\
\hline From land & $14.8 \%(n=4)$ & $59.2 \%(n=16)$ & $26.0 \%(n=7)$ \\
From on boat & $33.3 \%(n=9)$ & $40.7 \%(n=11)$ & $26.0 \%(n=7)$
\end{tabular}


"I believe the furthest away [boats are] from the eelgrass and destroying it, the better." (Participant 18)

Other reasons for selecting certain mooring buoy scenarios related to visitor experience. From the land perspective, it was noted that proposed relocation provides better views that are not "dominated" by boats. In contrast, some participants favored the current scenario when discussing visitor experience from the boater perspective, noting that this scenario provides a better view for boaters, gives easier access to shore, and feels less crowded in terms of the presence of surrounding moored boats. Some focus group participants were experienced boaters and provided comments drawing from their own experiences; for example, it was noted that the current scenario would be more favorable to many boaters as they would feel more sheltered from winds.

\footnotetext{
"From land-boats dominate seascape...From boat-better view of spit, quicker across to land." (Participant 12)

"Personal [preference] is current location because of distance and land [adjacency] when moored for protection from gales." (Participant 21)

"From land more sense of space and privacy. From boat closer to beach, more protected from... winds, less of a row to shore, not as close to other boats." (Participant 26)
}

It is interesting to note that sound was used in addition to the visuals for assessing mooring buoy scenarios. A sound clip of a boat motor played when participants traveled to the park's shore using the dinghy feature of the geovisualization, and the extended length of time this clip ran when in the proposed relocation scenario was disfavored by one participant, who commented on the potential increase in noise pollution. The participant was in favor of protecting the eelgrass, but was conflicted with the trade-off involving increased acoustic disturbance in nearshore areas.

"I want the boats to be farther from the shore and out of the...eelgrass, however I don't like the trade-off of more noise and longer noise of motor boats coming ashore." (Participant 11)

In addition to providing feedback on scenarios, suggestions for alternative approaches to the mooring issue were brought forward during discussion sessions. One suggestion involved building more dock infrastructure to increase space for boat moorage near the park, while potentially decreasing anchoring damage throughout the eelgrass meadows. When discussing this suggestion, it was noted that the geovisualization could be used for engaging boater stakeholders by displaying different dock locations or extensions and allowing boaters to comment on which options are most favorable (and why).

\section{Dog Management}

Similar to the other scenario exercises, participants were asked to rank the dog management scenarios in order of most to least preferred. Of the three scenarios, high preferences were most commonly observed with the increased awareness scenario, with
44.4\% selected it as first preference, $37.0 \%$ selected it as second and only $3.7 \%$ selected it as last (third) preference (Table 3 ). Preferences for the other two scenarios, i.e., current situation and no dogs scenarios, were comparable to one another. Slightly more participants provided a top ranking to the current situation scenario $(25.9 \%)$ than was observed with the no dogs scenario (22.2\%), but the current situation scenario was also ranked as last preference by more people (current situation-37.0\%; no dogs-29.6\%) and second preference by less people (current situation-14.8\%; no dogs-25.9\%).

Dog management was a controversial subject, and in some focus groups, exploring the scenarios sparked heated discussion around the problems associated with off-leash dogs in parks. Participants who selected the no dogs scenario as their first preference commented on potential dog-related issues, such as ecological disturbances (e.g., chasing birds), social nuisances (e.g., making noise), and safety concerns (e.g., potential for hurting people). Comments were also made about dog owners, alluding to how achieving complete compliance with on-leash regulations among this user group would be unlikely.

\footnotetext{
"Dogs chase birds, are noisy and not always to be trusted not to hurt people. I understand the companionship factor but non-dog people have rights too." (Participant 22)

"Onus is on the owners. Most dog owners are not responsible." (Participant 5)
}

Participants who selected the increased awareness scenario generally recognized the potential problems associated with offleash dogs, while they held a more favorable view of dogs within parks and recognized their presence to be important to certain park users (and thus park visitors). Participants favored the implementation of signage within the scenario, and (unlike the fencing scenario signage) positive comments were made about its aesthetics. The addition of Parks Canada staff was met with more hesitation than the signage because of the costs associated with employing summer students. However, it was noted in one of the focus groups that these expenses could be reframed as a benefit because it involves giving students summer employment and work experience.

"I think allowing dogs access to island is great but should be leashed so as not to destroy the grasses and chase wild life." (Participant 24)

"Try gentle encouragement to enforce leash use. [This scenario] employs a student." (Participant 10)

"I thought the sign (all dogs on a leash) looks attractive and firm enough." (Participant 19)

Participants who indicated preference for the current situation also recognized the potential issues associated with off-leash dogs, but like those who showed preference for increased awareness, they were amenable to dogs within the park. Some participants indicated they preferred the current situation with "enhancements," for example, the implementation of signage but not necessarily increased Parks Canada presence. 
TABLE 3 | Percentages of participants indicating preferences for dog management scenarios.

\begin{tabular}{lcccc}
\hline Preference & \multicolumn{2}{c}{ Dog management approach } & No response \\
\cline { 2 - 4 } & Current situation & No dogs & $\begin{array}{c}\text { Increased } \\
\text { awareness }\end{array}$ & \\
\hline First & $25.9 \%(n=7)$ & $22.2 \%(n=6)$ & $\begin{array}{c}44.4 \% \\
(n=12)\end{array}$ & $7.5 \%(n=2)$ \\
Second & $14.8 \%(n=2)$ & $25.9 \%(n=7)$ & $\begin{array}{c}37.0 \% \\
(n=10)\end{array}$ & $22.2 \%(n=6)$ \\
Third & $37.0 \%(n=10)$ & $29.6 \%(n=8)$ & $\begin{array}{c}3.7 \% \\
(n=10)\end{array}$ & $29.6 \%(n=8)$ \\
& & & &
\end{tabular}

Another participant who selected the current situation preference suggested an alternative to increasing Parks Canada presence or banning dogs, which was to create a "dog area" that restricted dog access to particular spaces. Following this suggestion, the geovisualization was used to explore potentially viable locations for such an area.

\section{"Signage to ask for leash use is most useful...A shame to ban dogs." (Participant 26) \\ "Provide a separate area where dogs can be off leash." (Participant 12)}

It is worth noting that dog scenarios were the last to be examined; therefore, participants encountered the dog running up the spit and disturbing the gulls prior to exploring these scenarios. In some cases, this previous "exposure" to the off-leash dog behavior might have factored into participants' decisions around dog scenarios. For example, one participant alluded to being aware of the potential disturbance the off-leash dog was causing while exploring fencing scenarios as she noted to have frequently heard the dog barking. In addition, it is possible that the exposure to the dog also influenced decisions around fencing scenarios, as some participants made reference to effectiveness of certain fencing materials in keeping out dogs (as well as people). Such observations demonstrate how realistic, dynamic geovisualizations can be used for gaining a more holistic understanding of scenarios, rather than treating different scenarios as isolated actions or events.

\section{Usefulness and User-Friendliness}

Participants rated the geovisualization's usefulness for assessing the scenarios on a scale of 1 (i.e., "not at all") to 10 (i.e., "extremely well") (Figure 9), and results indicate that geovisualization was considered useful for scenarios involving fencing $(M=7.96$, $S D=2.37)$ and mooring buoys $(M=7.6, S D=2.67)$. In both cases, single sample $t$-tests (one-tailed) provided strong evidence for supporting the claim that the average ratings exceeded a "halfway" score (i.e., 5.5), meaning they tended toward higher ratings [fencing: $t_{(24)}=5.19, p<0.001$; mooring buoys: $\left.t_{(22)}=3.41, p<0.001\right]$. Ratings concerning the geovisualization's usefulness for dog scenarios were more mixed $(M=6.10$, $S D=3.34)$, and in contrast to the other scenarios, statistical

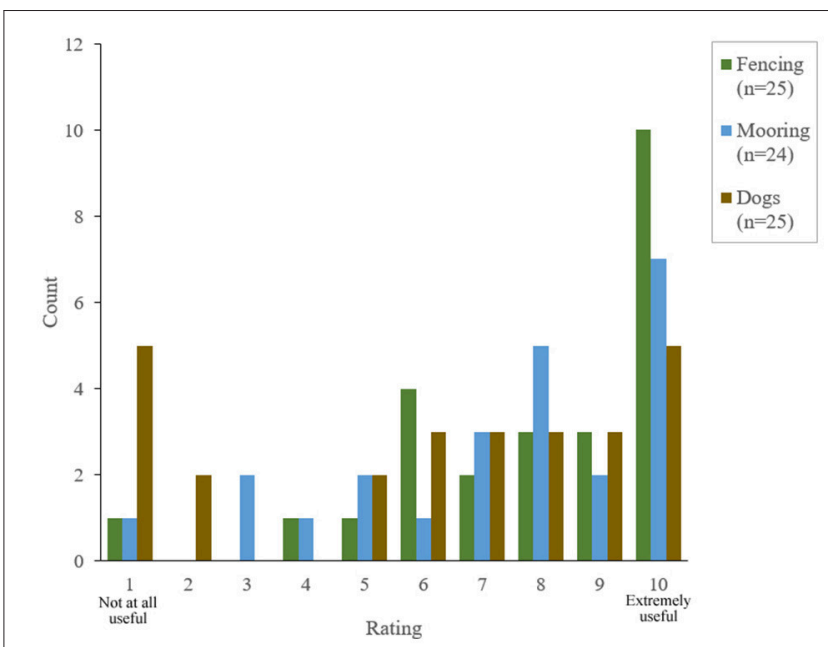

FIGURE 9 | Distribution of usefulness ratings for using geovisualization to assess scenarios. The $\mathrm{x}$-axis represents usefulness ratings indicated by participants using a scale from 1 to 10 . The $y$-axis represents number of participants that selected a particular rating score.

evidence was not found to support the notion that the average rating exceeded a halfway score $\left[t_{(26)}=0.937, p=0.179\right]$.

As presented in Sections Fencing Materials and Fencing Configuration, preferences for fencing options strongly related to perceptions around functionality and aesthetics, and participants indicated that the geovisualization helped them come to conclusions regarding these properties. Other feedback on the usefulness of geovisualization in assessing fencing scenarios included comments around how it helped in remembering what the environment looked like and (thus) allowed for strong contextualization of the scenarios. Some participants considered the geovisualization more useful for certain aspects of fencing scenarios then others (e.g., one participant noted that it was more useful for assessing signs than fences). Some participants claimed that they could come to similar decisions around fencing scenarios using maps, alluding to the idea that the geovisualization would not be entirely necessary for this purpose. However, multiple focus group participants expressed that they were quite comfortable with map-based visuals, whereas others without the same level of comfort with such a visual medium might respond differently (Lewis and Sheppard, 2006). Overall, participants commented positively around the fencing application.

"Very clear to see the various options. What looks pleasing, most
effective fence for habitat, etc." (Participant 26)

Participants noted that the geovisualization helped with certain aspects of the mooring buoy scenarios. In particular, comments were made around how it clearly showed potential effects to the viewshed. Other aspects of the geovisualization received mixed responses. For example, while one participant expressed appreciation for being able to experience travel times from shipto-shore on the dinghy, another noted that boaters might already 
have a sense of this and this feature is not too valuable for forming opinions. In addition, as with the fencing scenarios, some participants mentioned that they could make similar decisions using just maps, and it was noted in one of the group discussions that maps might be a more appropriate tool for assessing mooring buoy scenarios.

Impressions of the geovisualization's usefulness for assessing dog scenarios were more mixed than with the other scenarios. Some participants expressed that people could engage in discussion around dog management without the help of the geovisualization. It was actually noted that visual aids in general were not necessary for this discussion, and this differed from critiques of fencing and mooring buoy scenario applications in which maps were suggested to be potentially more useful tools. Other participants regarded the dog management application more positively, and found that the geovisualization conveyed the issue well. During group discussion, one participant noted that she did not want to "see that," referring to the off-leash dog disturbing the birds. This sentiment indicated that the geovisualization at least was successful in bringing beliefs and concerns to mind, if not providing new understanding around the dog management issues.

\footnotetext{
"Not as necessary as other features of program. Visually realistic but verbal or text conjure enough of an image to form an opinion.” (Participant 26)

"Certainly gets the point across and prepares people for their visit." (Participant 17)
}

Participant feedback indicated that the perceived usefulness of the geovisualization was associated with user-friendliness. Mean rating for user-friendliness was $6.81(S D=2.40)$ and statistical evidence exists for claiming that this exceeds a halfway score $\left[t_{(20)}=3.32, p=0.002\right]$. Participants nevertheless commented on how technical troubles interfered with the use of the tool. For example, some participants commented on difficulties navigating the virtual environment when exploring fencing scenarios, and this affected how useful the tool was for assessing these scenarios. As another example, participants frequently experienced difficulties boarding the dinghy and traveling to shore. Many participants admitted that these difficulties were in part because they lacked technical expertise, and they noted that perhaps more technologically adept users would not experience the same issues. However, this is still problematic in the context of this research, as this work is premised on the idea that geovisualizations can be used to engage diverse groups and not just the technologically adept. Alternatively, it was noted that scenarios could be effectively examined with the researcher acting as facilitator and operating the controls, suggesting that user control is not necessary for the geovisualization to be considered a useful tool. In fact, this was commonly noted to be preferable by many participants, as it allowed them to focus on the scenarios themselves rather than on how to operate the tool.

"I find all the tech computer for each person confusing. I preferred the presenter doing the tech stuff." (Participant 20)
Other comments around the usefulness of the geovisualization related to the supporting materials, specifically maps and cost estimates. Most agreed that the maps complemented the geovisualization well and provided better understanding of the scenarios. In some group discussions, maps were described as "essential" supporting materials. In contrast, only some participants found cost information useful, whereas others noted that it did not contribute heavily to decisions around scenarios. Those who did not find cost information particularly helpful noted that their decisions were based more on functionality or attractiveness, and it was mentioned that financial expenses were more a concern for those controlling the budget (i.e., Parks Canada) rather than park users.

"The maps were extremely useful-the cost estimates not so
much - they would in any case have to be measured against the
usefulness or attractiveness of a given design." (Participant 19)

\section{Familiarity}

A series of two-sample $t$-tests (two-tailed) were conducted to examine whether familiarity with Sidney Spit influenced how useful participants found the geovisualization to be for evaluating scenarios. However, no statistical evidence was found to support a difference in rating scores when comparing participants that were "primed" by visiting the park prior to the focus group $(n=16)$ with those who were not $(n=11)$, and this was the case for all scenario types [fencing- $t_{(23)}=0.577, p=0.569$; mooring buoys $-t_{(22)}=2.05, p=0.053$; dog management$\left.t_{(24)}=-0.065, p=0.949\right]$. Similarly, no differences were found between participants classified as "familiar" in terms of previous visits to the park $(n=14)$ and the other participants $(n=13)$ for any scenario types [fencing $-t_{(23)}=-1.89, p=0.07$; mooring buoys $-t_{(22)}=-0.928, p=0.364$; dog management$\left.t_{(24)}=-0.144, p=0.887\right]$.

Although familiarity did not appear to affect perceived usefulness of the geovisualization, chi-squared analysis provided evidence of effects on participant preferences for scenarios. In particular, a significant effect was found with priming and preference toward fencing configuration, where west side only scenarios were more likely selected by primed participants $\left(\chi^{2}=4.11, p=0.043\right)$. Such an observation might relate to the fact that participants were asked to walk to the north end of the spit when taken to the park, and (based on researcher observations) the participants themselves approached the north end from the west side. Differences in fencing selection were observed only with priming and not with those classified as familiar in terms of previous visitation $\left(\chi^{2}=0.309, p=0.579\right)$, which supports the notion that scenario selection might be influenced by recent experiences.

"Probably more [foot] traffic on the west side." (Participant 6)

Significant effects were not observed with preferences around fencing materials in both primed $\left(\chi^{2}=0.003, p=0.957\right)$ and familiar-classified cases $\left(\chi^{2}=2.84, p=0.092\right)$. In addition, no 
effects were observed with mooring buoy scenarios ${ }^{6}$ (primed: $\chi^{2}=3.64, p=0.056$; familiar-classified: $\chi^{2}=0.484, p=0.489$ ) and dog management scenarios (primed: $\chi^{2}=0.468, p=0.493$; familiar-classified: $\chi^{2}=0.302, p=0.583$ ).

\section{DISCUSSION}

Building scenarios within realistic geovisualizations requires modeling both space and place (Newell et al., 2017). That is, it involves capturing geometrical relationships to ensure scenarios are spatially accurate, while also working with realistic elements that can be recognized as real-world items and (thusly) hold potential to speak to people's sense of place in different ways (Newell and Canessa, 2015). For example, the fencing configurations of the geovisualization in this research assumed primarily spatial properties, whereas the fencing materials and designs built upon the configurations added meaningful objects that people could respond to with place-based preferences. Such a modeling process is reflective of Tuan's $(1977,6)$ heavily cited comment on place, who noted that "undifferentiated space becomes place when we endow it with value." In essence, scenario modeling within the geovisualization involved organizing abstract shapes and vectors (i.e., reference maps), and then layering them with objects and textures that transformed them into entities imbued with meaning and value (e.g., fences, boats, gulls, people, etc.).

A particular advantage of modeling place with space was that it allowed for a more comprehensive assessment of scenarios, as building elements with high degrees of realism allowed geovisualization users the opportunity to respond to aspects of the scenarios that were not initially intended for assessment. For example, many participants in the study reacted negatively toward the design and wording of the fencing signage, and they subsequently suggested improvements that could lead to better cooperation from visitors in terms of keeping people out of restoration areas. In addition, modeling place within this study also involved the development of a soundscape, following the reasoning that sense of place is influenced by sensory inputs beyond just sight (Tuan, 1975), and this too allowed for more comprehensive assessments. The initial intention of incorporating sound into the geovisualization was simply to create a better representation of coastal place (Newell et al., 2017). However, as noted by Lindquist and Lange (2014), this can also contribute to a visualization's usefulness because people assess landscape changes through multiple senses. In accordance with this notion, the current study found that audio stimuli contributed to user assessment of scenarios. The soundscape was particularly useful for assessing temporal aspects of scenarios, as sound is inherently dynamic (Worboys and Duckham, 2004), and it can be assessed in terms of outcomes or level of impact occurring over a duration. For example, a participant

\footnotetext{
${ }^{6}$ Preferences for mooring buoy scenarios were considered in terms of participant selections for both on land and from aboard boats perspectives (e.g., current location and current location, proposed relocation and current location, etc.) because participant comments indicated that these selections were not independent from one another.
}

identified sound pollution through longer ship-to-shore travel as a disadvantage of the proposed relocation mooring buoy scenario, indicating that the incorporation of sound into the geovisualization allowed her to come to this conclusion.

Modeling place with space does present opportunities but is also associated with certain challenges. In particular, it requires constant consideration around how elements are modeled and what specific identities are bestowed upon them. Examples of such considerations are seen with the dog management scenarios. Previous research has found that people hold perceptions around certain dog breeds in terms of personalities and temperaments (e.g., Gunter et al., 2016), and thus, it is possible that the appearances of the dog models could also play a role in how some people responded to dog management scenarios. Previous research has also found that perceptions of and feelings toward virtual human characters can differ depending on whether they are modeled as male or female (e.g., Yanghee and Baylor, 2006), and in this study, decisions had to be made as to what gender to portray the Parks Canada staff. Ultimately, the models were arbitrarily assigned genders, consisting of one male and one female. It is uncertain as to whether responses to scenarios would differ if instead both models were of the same gender or if genders of the current models were switched.

Modeling place also brings forward considerations around scalability and whether realistic geovisualizations are appropriate tools for planning in larger areas (as opposed to just site specific places). Building geovisualizations with high levels of detail can limit the geographical extent that can feasibly be modeled. As these are place-based tools, however, modeling larger areas might not be necessary or even appropriate for this type of visualization. The geovisualization is experienced from the first-person perspective, which Orland et al. (2001) described as an "egocentric" approach to visualization and noted that such a perspective is best suited for ground-level assessments concerning decisions that affect smaller areas. Aligning with this notion, the geovisualization was equipped with a teleportation function in order to reach different locations without having to spend excessive time walking through the 85hectare space, and this feature was used frequently throughout the focus group sessions. In addition, although challenges exist in modeling large areas with great detail, this does not interfere with the geovisualization's capacity for allowing users to interact and assess impacts to spatially expansive areas. For example, participants in this research assessed scenarios that held implications for the viewshed (i.e., mooring buy scenarios), and the modeled viewshed elements represented geography extending a considerable distance beyond the Sidney Spit site in the real-world setting.

Navigability appeared to enhance the geovisualization's capacity as a tool for inclusive approaches to planning, particularly for scenarios specific to the coastal context. As noted in Section Introduction, the purpose of implementing navigability was to allow people to cross the land-sea interface, and this ability to enter the marine environment contributed to understandings and assessments of the mooring buoy scenarios. Certain niche user such as SCUBA divers can develop familiarity and place-relationships with marine environments 
(e.g., Moskwa, 2012), but most coastal users experience these places from positions above the water surface and thus the marine realm consists of extra-perceptual places, i.e., places that have not been personally experienced (Goodey, 1974). This study found evidence that navigable land-to-sea geovisualizations can help overcome the extra-perceptual nature of the marine. It was noted that the ability to explore the underwater environment and seeing eelgrass ecosystems helped convey the significance of efforts for protecting these ecosystems (i.e., relocating mooring buoys to reduce anchoring in eelgrass meadows). Such an observation is encouraging as it suggests that geovisualizations can contribute to decisions that are based on a more holistic understanding of coastal environments.

Another advantage of incorporating navigability into the geovisualization was that it allowed users to consider options beyond the pre-designed scenarios, as they could explore areas from the first-person perspective to get a sense as to whether said areas could provide alternatives to what was proposed. For example, the geovisualization was used to explore new areas for signage in the fencing scenario exercise and suitable locations for possible dog areas in the dog management exercise. Referring back to Orland et al. (2001) discussion on egocentric visualizations, they commented on such forms of visualization as beneficial in that they allow planners to examine a situation from the "inside" and make ground-level management decisions. The findings from this study confirm such a notion; they indicate that realistic, navigable geovisualizations allow users the ability to consider multiple management options from different angles.

The geovisualization demonstrated to be valuable for examining aesthetics, and such a feature was particularly useful for assessing fencing scenarios. Feedback from focus groups indicated that the geovisualization was helpful for considering how certain fencing materials might align or conflict with the surrounding environment. Such aesthetic considerations are important when thinking about fostering positive visitor experience and sense of place (e.g., Collins and Kearns, 2010). The findings from this study thus align with previous research that found visualizations to be useful for showing how constructed elements can affect the "character" of a place (Salter et al., 2009). In addition, the geovisualization demonstrated capacity for allowing users to think about aesthetics in the context of other factors, particularly by illuminating trade-offs between aesthetics and functionality (e.g., wooden split-rail fencing vs. mesh fencing). The geovisualization also allowed users to identify circumstances where the appearance of a fence might actually be counteractive to functionality, namely with the rope which was described as "inviting" for children to come over and play with it.

Related to aesthetics, the geovisualization also exhibited to be useful for examining viewsheds and assessing scenarios that hold implications for views. Such an application is important for geovisualizations employed in the coastal context because many coastal users have strong value for the view out the ocean (Thompson, 2007), and (in some cases) these views can be important in terms of people's attachment to place (e.g., Devine-Wright and Howes, 2010). Feedback on the mooring buoy scenarios suggested that the geovisualization can be used for viewshed analysis, as geovisualization users indicated that their preferences for certain scenarios were based on improving ocean views (i.e., moored buoys "dominate" the seascape less when moving buoys further away from shore). Coastal geovisualizations therefore could be valuable in other cases where viewsheds might be impacted, and perhaps could play an important role in situations where viewshed impacts might be substantial and proposed plans are controversial, such as with offshore wind farms (Phadke, 2010).

Applications in which the geovisualization was regarded more critically included the dog management scenarios, as some participants indicated that discussion around dog management could be done without visual aids. Dog management scenarios differed from fencing and mooring buoy scenarios in that they primarily involved modeling of place and involved little spatial modeling. Places can have fuzzy boundaries that are not always easily defined spatially (Collins and Kearns, 2010; McLain et al., 2013), and such was true for the dog scenarios where even though models were assigned locations (i.e., dogs, owners, and Parks Canada staff), it was generally understood that they would not be bound to these locations in the realworld. In contrast, fencing and mooring buoys were highly spatial in nature, and most agreed that some form of visual media would be useful for these scenarios (i.e., maps, if not the geovisualization). Such a finding suggests that people might value geovisualizations for representing data on place and space, but have more mixed opinions when solely (or at least primarily) place-based information is represented. However, it is important to recognize that perceived value (or lack thereof) does not necessarily equate with actual usefulness, and it is possible that participants were responding to the conveyed dog scenarios on a more subconscious level, where the usefulness of the tool might not be immediately obvious. Sense of place encompasses visceral feelings and emotions (Tuan, 1975), and there was evidence in the study that people were responding to dog scenarios on such a level, such as with the comment around not wanting to "see that" in reference to dogs disturbing birds and the mention of being aware of the dog barking when examining fencing scenarios. Therefore, it is possible that modeling scenarios that are much more related to place characteristics than spatial properties can be useful for examining scenarios and making decisions, even if the value is not immediately apparent to the geovisualization users.

Perceptions around the geovisualization's usefulness for scenario assessment was tightly linked with opinions on the tool's user-friendliness, or in the case of many users within this study, the lack of user-friendliness. Newell et al. (2017) found that user control contributed to the sense of being in a real-world environment when freely exploring the geovisualization. This study observed that user control was regarded more critically when it came to targeted tasks, i.e., examining scenarios. It is possible that a different user interface and method of control would have resolved these issues. For example, Smith et al. (2012) interactive visualization of forestry management scenarios in southeastern Tasmania was noted by users to be relatively easy to use. It was controlled through simple click and drag mouse operations, as well as being equipped with a user interface with text that described the scenarios and identified the different features and functions of the tool (Smith et al., 
2012). Alternatively, providing everyone with user control might not be necessary, as many of the study participants indicated they preferred having the geovisualization facilitated by the researcher because this allowed them to concentrate on aspects and implications of the scenarios rather than computer controls. Ultimately, many participants shifted away from operating the tool themselves toward asking the researcher to display certain aspects of scenarios and the virtual environment, as this gave them a certain degree of control without having to familiarize with keyboard commands. This observation aligns with Salter et al. (2009) findings from a study on using visualization for participatory planning on Bowen Island (BC, Canada). They found that study participants rated the usefulness of the tool highly even though participants interacted with it by giving navigational instructions to a computer operator and highlighting features on the screen with a laser pen (Salter et al., 2009). The findings of this research and Salter et al. (2009) study indicate that dynamic, navigable geovisualizations can be effective planning tools without stakeholders having direct control of the tools. However, as posited by Schroth et al. (2011), it is important to recognize that taking this approach requires operators of the geovisualizations to have strong facilitation skills and the ability to effectively incorporate the tool within planning discussions.

The geovisualization's usefulness also appeared to be related to the availability of certain supporting materials, namely, the fencing and mooring buoy scenario maps. In previous visualization research, Lewis and Sheppard (2006) noted that some stakeholders might respond better to realistic landscape visualizations than abstract maps when assessing scenarios. Yet, they did not discount the value of maps and suggested using a combination of visuals. The findings of this study support this suggestion, as many participants expressed the usefulness of complementary maps with some regarding these as "essential" supporting materials. In contrast, cost estimates were not widely regarded as useful supporting materials. These findings initially appear to contradict the assertions of Grêt-Regamey et al. (2013), who posited that linking cost metrics to visualization scenarios enhances capacity for scenario assessment because it makes trade-offs explicit. However, it is important to consider the geovisualization users when thinking about what would be regarded as a "trade-off." Although park management efforts use public funds, focus group participants were not among those who have direct control over the Parks Canada budget and thus were somewhat "removed" from cost implications. Consequently, expenses such as the costs of different fencing materials did not factor as strongly into assessments as did other considerations related to more personal concerns and interests, such as those associated with ecological values (i.e., protection of vegetation) and visitor experience (i.e., park aesthetics).

Unlike user-friendliness and supporting materials, perceptions around the geovisualization's usefulness did not appear linked or related to familiarity with Sidney Spit. This could be because the participants have familiarity with similar coastal environments and other coastal parks located within the greater area (Newell et al., 2017), thus were able to make place-based decisions on that basis. However, this being said, familiarity was observed to influence the scenario assessment itself, particularly with the primed groups and fencing configuration. Primed participants appeared more amenable to the west side only fencing configuration, and this could be because of the participants' personal experiences walking up the west beach when approaching the north end of the spit. If this supposition is correct, it demonstrates that recent experiences with real-world places influence how we regard and interact with virtual representations of these places, and accordingly, recent place experiences of geovisualization users should be considered when using these tools for planning purposes.

\section{CONCLUSION}

This study found that coastal geovisualizations show promise as tools for engaging different people in assessment and discussion around planning scenarios. The geovisualization was considered more useful for examining certain management issues over others; however, by modeling both place and space, the tool demonstrated that it could be used for assessing aspects and considering options beyond simply the options and scenarios developed prior to planning sessions. The geovisualization also provided a platform for coastal users to share experiences and perspectives associated with their specific user group (e.g., boaters discussing closer mooring buoys as more appealing because of feelings of being more sheltered from wind), thereby allowing for planning discussions with diverse user interests in mind.

The findings from the study indicate that coastal geovisualizations can be useful for providing diverse stakeholders with comprehensive understanding of local issues and potential options, while also serving as platforms for gaining a better understanding of different stakeholder interests and perspectives. This indicates that coastal geovisualizations have potential as tools for facilitating inclusive, collaborative planning efforts. This being said, it is important to recognize that the changes and consequences depicted through the scenarios in this research were relatively modest (e.g., erecting fences, changing positions of mooring buoys, adding Parks Canada staff, etc.). Future research can build on this work by developing interactive geovisualizations that depict more dramatic changes to coastal places (e.g., new marina, off-shore wind turbines, new commercial buildings, etc.). In addition, this study follows a research approach involving small numbers of participants for primarily collecting qualitative data (e.g., Lewis and Sheppard; Salter et al., 2009). Future research around this form of geovisualization can take a different approach. Namely, future studies can involve larger sample sizes and survey-based data collection to examine how a (theoretically) wider diversity of people regard the usefulness and userfriendliness of the tools (e.g., Smith et al., 2012) and show preferences for different scenarios (Groulx et al., 2017). Such research would be particularly valuable for examining questions around how different demographic aspects interact with and respond to the tools. For example, how do younger groups that (presumably) have had more early life exposure to computer 
technology regard usefulness and user-friendliness of these geovisualizations? Overall, this study has found that realistic immersive geovisualizations show promise as tools for inclusive approaches to coastal planning and management, and further research can continue to explore this potential.

\section{ETHICS STATEMENT}

Ethical review was approved by the Human Research Ethics Board (HREB) at the University of Victoria (Protocol Number: 14-200). Participants reviewed and signed a "Letter of Information for Participant Consent" prior to engaging in focus groups, and comments/feedback from participants was only used if letter was signed and collected.

\section{AUTHOR CONTRIBUTIONS}

RN conducted the fieldwork, built the geovisualization, led the focus groups, analyzed the data, and wrote the first draft of the paper. $\mathrm{RC}$ is RN's $\mathrm{PhD}$ supervisor. $\mathrm{RC}$ devised the original

\section{REFERENCES}

Antos, M. J., Ehmke, G. C., Tzaros, C. L., and Weston, M. A. (2007). Unauthorised human use of an urban coastal wetland sanctuary: current and future patterns. Landsc. Urban Plan. 80, 173-183. doi: 10.1016/j.landurbplan.2006.07.005

Beegle-Krause, C. J., Vance, T., Reusser, D., Stuebe, D., and Howlett, E. (2009). "Pelagic habitat visualization: the need for a third (and fourth) dimension: habitatspace," in 11th International Conference on Estuarine and Coastal Modeling, American Society of Civil Engineers, ed M. L. Spaulding (Seattle, WA), 187-200.

Bishop, I. D., and Rohrmann, B. (2003). Subjective responses to simulated and real environments: a comparison. Lands. Urban Plann. 65, 261-277. doi: 10.1016/S0169-2046(03)00070-7

Bowen, R. E., and Riley, C. (2003). Socio-economic indicators and integrated coastal management. Ocean Coast. Manag. 46, 299-312. doi: 10.1016/S0964-5691(03)00008-5

Canessa, R., Newell, R., and Brandon, C. (2015). "Uncovering the oceans through marinescape geovisualizations," in Ocean Solutions, Earth Solutions, ed D. Wright (Redlands, CA: Esri), 243-246.

Cicin-Sain, B., and Knecht, R. W. (1998). Integrated Coastal and Ocean Management: Concepts and Practices. Washington, DC: Island Press.

Cicin-Sain, B. (1993). Sustainable development and integrated coastal management. Ocean Coast. Manag. 21, 11-43. doi: 10.1016/0964-5691 (93)90019-U

Collins, D., and Kearns, R. (2010). It's a gestalt experience: landscape values and development pressure in Hawke's Bay, New Zealand. Geoforum 41, 435-446. doi: 10.1016/j.geoforum.2009.11.010

COSEWIC (2009). Assessment and Status Report on the Edwards' Beach Moth Anarta edwardsii in Canada. Species at Risk Public Registry[webpage]. Government of Canada. Available online at: https://www.registrelepsararegistry.gc.ca/default.asp?lang=Enandn=0BB2C96B- 1

Devine-Wright, P., and Howes, Y. (2010). Disruption to place attachment and the protection of restorative environments: a wind energy case study. J. Environ. Psychol. 30, 271-280. doi: 10.1016/j.jenvp.2010.01.008

Devoy, R. J. N. (2016). Fanore Beach and Dune Management Report: Current Problems and Planning for the Future. Report Commissioned by Burren and Cliffs of Moher Geopark Tourism for Conservation LIFE Project, LIFE 11/IE/922, Clare County Council. Clare, Ireland.

Fisheries and Oceans Canada (2014). Shellfish-Species and Limits Table [webpage]. Government of Canada. Available online at: http://www.pac.dfo-mpo.gc.ca/fm$\mathrm{gp} / \mathrm{rec} / \mathrm{species-especes/shelltable-tableaucoquille-eng.htm}$ concept for the project, provided guidance around the project plan, development and activities, and contributed to final paper. TS is on RN's doctoral committee, and also is a Parks Canada partner for the project. TS aided in acquiring data for building the geovisualization (i.e., data that was described as "obtained from Parks Canada"), provided guidance on conducting the research, helped organized the Parks Canada focus group and collected notes on feedback, and contributed to the final paper.

\section{FUNDING}

We gratefully acknowledge the funding from the Social Sciences and Humanities Research Council (SSHRC), who provided funding for the greater research project entitled "Seascape Visualization for Marine Conservation Planning and Outreach" (grant number: 435-2013-01948). In addition, we acknowledge SSHRC for the support provided to the first author through the Joseph-Armand Bombardier Canada Graduate Scholarships Program (Doctoral Scholarships).

Garriga, M., and Losada, I. J. (2010). Education and training for integrated coastal zone management in Europe. Ocean Coast Manag. 53, 89-98. doi: 10.1016/j.ocecoaman.2010.01.004

Gold, C. M., Chau, M., Dzieszko, M., and Goralski, R. (2004). The marine GISDynamic GIS in action. Int. Arch. Photogramm. 35, 688-693. Available online at: http://www.isprs.org/proceedings/XXXV/congress/comm2/comm2.aspx

Goodey, B. (1974). Images of Place: Essays on Environmental Perception, Communications and Education Vol. 30. Centre for Urban and Regional Studies, University of Birmingham, Birmingham.

Grêt-Regamey, A., Celio, E., Klein, T. M., and Hayek, U. W. (2013). Understanding ecosystem services trade-offs with interactive procedural modeling for sustainable urban planning. Landsc. Urban Plan. 109, 107-116. doi: 10.1016/j.landurbplan.2012.10.011

Groulx, M., Lemieux, C. J., Lewis, J. L., and Brown, S. (2017). Understanding consumer behaviour and adaptation planning responses to climatedriven environmental change in Canada's parks and protected areas: a climate futures capes approach. J. Environ. Plann. Manag. 60, 1016-1035. doi: 10.1080/09640568.2016.1192024

Gunter, L. M., Barber, R. T., and Wynne, C. D. (2016). What's in a name? Effect of breed perceptions and labeling on attractiveness, adoptions and length of stay for pit-bull-type dogs. PLOS ONE 11:e0146857. doi: 10.1371/journal.pone. 0146857

Hong-ge, Y. (2010). "The realization of flight simulation system based on openGL," in 2010 Second International Conference on Information Technology and Computer Science (ITCS), IEEE (Washington, DC), 198-201.

Hu, J., Wan, W., Wang, R., and Yu, X. (2012). "Virtual reality platform for smart city based on sensor network and OSG engine," in 2012 International Conference on Audio, Language and Image Processing (ICALIP), IEEE (Shanghai), 1167-1171.

Isaacs, J. P., Gilmour, D. J., Blackwood, D. J., and Falconer, R. E. (2011). Immersive and non immersive 3D virtual city: decision support tool for urban sustainability. J. Inform. Technol. Constr. 16, 151-162. Available online at: http://www.itcon.org/paper/2011/10

Lafferty, K. D. (2001). Disturbance to wintering western snowy plovers. Biol. Conserv. 101, 315-325. doi: 10.1016/S0006-3207(01)00075-1

Lewis, J., and Sheppard, S. R. J. (2006). Culture and communication: can landscape visualization improve forest management consultation with indigenous communities? Landsc. Urban Plan. 77, 291-313. doi: 10.1016/j.landurbplan.2005.04.004

Lindquist, M., and Lange, E. (2014). "Sensory aspects of simulation and representation in landscape and environmental planning: a soundscape 
perspective," in Innovative Technologies in Urban Mapping, Vol. 10, eds A. Contin, P. Paolini, and R. Salerno (Cham: Springer International Publishing), 93-106.

Lovett, A., Appleton, K., Warren-Kretzschmar, B., and Von Haaren, C. (2015). Using 3D visualization methods in landscape planning: an evaluation of options and practical issues. Landsc. Urban Plan. 142, 85-94. doi: 10.1016/j.landurbplan.2015.02.021

Maurer, A. L. (1989). Sidney Spit Provincial Marine Park-Wildlife Viewing Development Plan. Victoria, BC: Parks Library, Government of British Columbia.

McLain, R., Poe, M., Biedenweg, K., Cerveny, L., Besser, D., and Blahna, D. (2013). Making sense of human ecology mapping: an overview of approaches to integrating socio-spatial data into environmental planning. Hum. Ecol. 41, 651-665. doi: 10.1007/s10745-013-9573-0

Moskwa, E. C. (2012). Exploring place attachment: an underwater perspective. Tour. Mar. Environ. 8, 33-46. doi: 10.3727/154427312X13262430524063

NCC (2015). NCC and the sea [webpage]. Nature Conservancy Canada. Victoria, BC. Available online at: http://www.natureconservancy.ca/en/where-we-work/ british-columbia/stories/ncc-and-the-sea.html

Newell, R., and Canessa, R. (2015). Seeing, believing, and feeling: the relationship between sense of place and geovisualization research. Spaces Flows 6, 15-30. doi: 10.18848/2154-8676/CGP/v06i04/53779

Newell, R., and Canessa, R. (2017). Picturing a place by the sea: geovisualizations as place-based tools for collaborative coastal management. Ocean Coast. Manag. 141, 29-42. doi: 10.1016/j.ocecoaman.2017.03.002

Newell, R., Canessa, R., and Sharma, T. (2017). Modeling both the space and place of coastal environments: exploring an approach for developing realistic geovisualizations of coastal places. Front. Mar. Sci. 4:87. doi: 10.3389/fmars.2017.00087

O’Neill, J. D., Costa, M., and Sharma, T. (2011). Remote sensing of shallow coastal benthic substrates: in situ spectra and mapping of eelgrass (Zostera marina) in the Gulf Islands National Park Reserve of Canada. Remote Sens. 3, 975-1005. doi: $10.3390 / \mathrm{rs} 3050975$

Orland, B., Budthimedhee, K., and Uusitalo, J. (2001). Considering virtual worlds as representations of landscape realities and as tools for landscape planning. Landsc. Urban Plan. 54, 139-148. doi: 10.1016/S0169-2046(01)00132-3

Parks Canada (2012). 2012 Visitor's Guide-Gulf Islands National Park Reserve [PDF document]. Government of Canada. Available online at: http:// publications.gc.ca/collections/collection_2012/pc/R61-24-2012-eng.pdf

Parks Canada (2014). Student Rates of Pay-Effective January 1, 2014 [webpage]. Government of Canada. Available online at: https://www.canada.ca/en/ treasury-board-secretariat/services/pay/rates-pay/student-rates-pay/studentrates-pay-2014.html

Phadke, R. (2010). Steel forests or smoke stacks: the politics of visualisation in the Cape Wind controversy. Env. Polit. 19, 1-20. doi: 10.1080/09644010903396051

Salter, J. D., Campbell, C., Journeay, M., and Sheppard, S. R. J. (2009). The digital workshop: exploring the use of interactive and immersive visualisation tools in participatory planning. J. Environ. Manage. 90, 2090-2101. doi: 10.1016/j.jenvman.2007.08.023

Schroth, O., Pond, E., Muir-Owen, S., Campbell, C., and Sheppard, S. R. J. (2009). Tools for the understanding of spatio-temporal climate scenarios in local planning: Kimberley (BC) case study. Swiss Nat. Sci. Found. Rep. PBEZP1-122976.
Schroth, O., Hayek, U. W., Lange, E., Sheppard, S. R. J., and Schmid, W. A. (2011). Multiple-case study of landscape visualizations as a tool in transdisciplinary planning workshops. Landsc. J. 30, 53-71. doi: 10.3368/ lj.30.1.53

Shackeroff, J. M., Hazen, E. L., and Crowder, L. B. (2009). “The oceans as peopled seascapes," in Ecosystem-Based Management for the Oceans, eds K. L. McLeod and H. M. Leslie (Washington, DC: Island Press), 33-54.

Sheppard, S. R. J., Shaw, A., Flanders, D., Burch, S., Wiek, A., Carmichael, J., et al. (2011). Future visioning of local climate change: a framework for community engagement and planning with scenarios and visualisation. Futures 43, 400-412. doi: 10.1016/j.futures.2011.01.009

Sheppard, S. R. J. (2001). Guidance for crystal ball gazers: developing a code of ethics for landscape visualization. Landsc. Urban Plan. 54, 183-199. doi: 10.1016/S0169-2046(01)00135-9

Smith, E. L., Bishop, I. D., Williams, K. J. H., and Ford, R. M. (2012). Scenario Chooser: an interactive approach to eliciting public landscape preferences. Landsc. Urban Plan. 106, 230-243. doi: 10.1016/j.landurbplan.2012. 03.013

Sorensen, J. (1997). National and international efforts at integrated coastal management: definitions, achievements, and lessons. Coast. Manag. 25, 3-41. doi: 10.1080/08920759709362308

Stocker, L., and Kennedy, D. (2009). Cultural models of the coast in Australia: toward sustainability. Coast. Manag. 37, 387-404. doi: 10.1080/08920750902855998

Thompson, R. (2007). Cultural models and shoreline social conflict. Coast. Manag. 35, 211-237. doi: 10.1080/08920750601042294

Tress, B., and Tress, G. (2003). Scenario visualisation for participatory landscape planning-a study from Denmark. Landsc. Urban Plan. 64, 161-178. doi: 10.1016/S0169-2046(02)00219-0

Tuan, Y. F. (1975). Place: an experiential perspective. Geogr. Rev. 65, 151-165. doi: $10.2307 / 213970$

Tuan, Y. F. (1977). Space and Place: the Perspective of Experience. Minneapolis, MN: University of Minnesota Press.

Williams, K. J., Weston, M. A., Henry, S., and Maguire, G. S. (2009). Birds and beaches, dogs and leashes: Dog owners' sense of obligation to leash dogs on beaches in Victoria, Australia. Hum. Dimens. Wildl. 14, 89-101. doi: 10.1080/10871200802649799

Worboys, M. F., and Duckham, M. (2004). GIS: A Computing Perspective, 2nd Edn. Boca Raton, FL: CRC Press.

Yanghee, K., and Baylor, A. L. (2006). A social-cognitive framework for pedagogical agents as learning companions. Educ. Technol. Res. Dev. 54, 569-596. doi: 10.1007/s11423-006-0637-3

Conflict of Interest Statement: The authors declare that the research was conducted in the absence of any commercial or financial relationships that could be construed as a potential conflict of interest.

Copyright (c) 2017 Newell, Canessa and Sharma. This is an open-access article distributed under the terms of the Creative Commons Attribution License (CC BY). The use, distribution or reproduction in other forums is permitted, provided the original author(s) or licensor are credited and that the original publication in this journal is cited, in accordance with accepted academic practice. No use, distribution or reproduction is permitted which does not comply with these terms. 